\title{
Evidências científicas sobre os fatores de estresse em profissionais de enfermagem que atuam na Unidade de Terapia Intensiva
}

Scientific evidence about stress factors in nursing professionals who work in the Intensive Care

Unit

Evidencia científica sobre factores de estrés en profesionales de enfermería que trabajan en la Unidad de Cuidados Intensivos

Airton César Leite

ORCID: https://orcid.org/0000-0001-7184-8488

Centro Universitário Santo Agostinho, Brasil E-mail: ainton.cesar2014@gmail.com

Mariana Pereira Barbosa Silva

ORCID: https://orcid.org/0000-0003-0852-8099 Universidade Estadual do Piauí, Brasil E-mail: marianapbsilvaa@gmail.com

Rayssa Stéfani Sousa Alves

ORCID: https://orcid.org/0000-0002-9666-675X Pontifícia Universidade Católica de Goiás, Brasil E-mail: rayssastefani02@gmail.com

Reilda de Sá Lima

ORCID: https://orcid.org/0000-0002-3582-4232

Centro Universitário Santo Agostinho, Brasil

E-mail: reilda_@hotmail.com

Francisca Cindy de Sousa Albuquerque

ORCID: https://orcid.org/0000-0001-7551-0265

Centro Universitário Santo Agostinho, Brasil

E-mail: f_cindy@outlook.com

Maria Bianca e Silva Lima

ORCID: https://orcid.org/0000-0002-9175-0434

Centro Universitário Santo Agostinho, Brasil

E-mail: mariabianca10075@gmail.com

Flávia Nunes Barbosa

ORCID: https://orcid.org/0000-0002-8101-2032

Universidade Federal do Piauí, Brasil

E-mail: flavianunes-cat@hotmail.com

Bárbara Pereira Gomes

ORCID: https://orcid.org/0000-0002-0590-2228

Centro Universitário UNIFACID, Brasil

E-mail: barbaraenfgomes@gmail.com

Thatielly Rodrigues de Morais Fé

ORCID: https://orcid.org/0000-0001-9400-1116

Faculdade Estácio de Teresina, Brasil

E-mail: thatiellymorais@outlook.com

Rafael de Assis de Brito

ORCID: https://orcid.org/0000-0002-6816-8489 Centro Universitário UNIFACID, Brasil

E-mail: enfrafaelbrito@gmail.com

Juliana Torres Avelino

ORCID: https://orcid.org/0000-0002-8732-1856

Centro Universitário Santo Agostinho, Brasil E-mail: Juliana_avelinno@hotmail.com

Clênio Oliveira Barrense

ORCID: https://orcid.org/0000-0003-1457-1317 Universidade Estadual do Piauí, Brasil E-mail: cleniobarrense@ yahoo.com.br

Márcia Bethania de Sousa Silva

ORCID: https://orcid.org/0000-0001-5059-7528

Centro Universitário Santo Agostinho, Brasil E-mail: marcia-bethania@hotmail.com 


\author{
Jailson Pereira de Sousa \\ ORCID: https://orcid.org/0000-0001-7650-7017 \\ Centro Universitário do Piauí, Brasil \\ E-mail: pereiradesousajailson@gmail.com \\ Laiana Dias Prudêncio \\ ORCID: https://orcid.org/0000-0002-0016-3868 \\ Centro Universitário Maurício de Nassau, Brasil \\ E-mail: laianadias568@gmail.com \\ Rihama Layla Rodrigues Costa \\ ORCID: https://orcid.org/0000-0001-9537-7561 \\ Centro Universitário UNINASSAU, Brasil \\ E-mail: rihamah_costa@hotmail.com \\ Layanne Cavalcante de Moura \\ ORCID: https://orcid.org/0000-0003-2781-1076 \\ Centro Universitário UNIFACID, Brasil \\ E-mail: layannecavalcante@hotmail.com \\ Pedro de Oliveira Nogueira \\ ORCID: https://orcid.org/0000-0002-8309-5759 \\ Universidade Paulista, Brasil \\ E-mail: pedro.on1514@gmail.com \\ Adson Gomes dos Santos \\ ORCID: https://orcid.org/0000-0002-3230-6165 \\ Universidade do Estado do Rio Grande do Norte, Brasil \\ E-mail: adsongomes@live.com \\ Amanda Costa Maciel \\ ORCID: https://orcid.org/0000-0002-2668-037X \\ Faculdade São Vicente de Pão de Açúcar, Brasil \\ E-mail: amandacmaciel@hotmail.com \\ Mariane Rangel Gomes Campos \\ ORCID: https://orcid.org/0000-0001-6000-8395 \\ Universidade Estácio de Sá, Brasil \\ E-mail: marianergc@gmail.com \\ Jhônata Santos Brito \\ ORCID: https://orcid.org/0000-0002-8161-5677 \\ Faculdade de Ciências e Empreendedorismo, Brasil \\ E-mail: jhonbrito12@gmail.com \\ Bianca Damasceno Nascimento \\ ORCID: https://orcid.org/0000-0001-5131-5369 \\ Universidade Federal de Alfenas, Brasil \\ E-mail: biancadamasceno21@gmail.com \\ Jeferson Moreira Dos Santos \\ ORCID: https://orcid.org/0000-0001-7807-1341 \\ Universidade do Estado da Bahia, Brasil \\ E-mail: Jeff.ibce73@gmail.com
}

\title{
Resumo
}

Analisar as evidências científicas sobre os fatores de estresse em profissionais de enfermagem que atuam na Unidade de Terapia Intensiva. Trata de uma revisão bibliográfica do método revisão integrativa da literatura, realizado nos meses de novembro e dezembro de 2020. A busca efetuou-se, através da Plataforma - BVS, utilizando as bases de dados (LILACS), (BDENF), e por meio do Portal Google Acadêmico, aderindo-se através dos descritores: "Estresse", "Profissionais de Enfermagem", "Unidade de Terapia Intensiva", combinados ao operador booleando "AND". As Unidades de Terapias Intensivas demonstram que os profissionais de enfermagem que atuam nesses ambientes enfrentam elevados níveis de estresse. Existe uma relação muito próxima entre a exposição diária a fatores estressores relacionados ao ambiente desgastante e cansativo e o estresse. Os profissionais de saúde, particularmente os que trabalham em Unidades de Terapia Intensiva (UTIs), estão em situação de vulnerabilidade para o desenvolvimento de quadros de estresse. Em uma UTI, a rotina de trabalho é marcada pela variabilidade, incerteza e risco, fatores que podem ser desencadeadores de estresse para muitos profissionais; além disso, o excesso de ruídos, o relacionamento com a equipe e a relação com os familiares e pacientes podem ser fontes adicionais de estresse nesse contexto. $\mathrm{O}$ enfermeiro e a instituição hospitalar devem reconhecer os estressores que estão presentes no trabalho e procurar mecanismos e estratégias de enfrentamento individual e coletivo para diminuir a ocorrência de estresse profissional.

Palavras-chave: Estresse; Profissionais de enfermagem; Unidade de Terapia Intensiva.

\section{Abstract}

Analyze the scientific evidence on stress factors in nursing professionals who work in the Intensive Care Unit. It deals with a bibliographic review of the integrative literature review method, carried out in the months of November and December 2020. The search was carried out, through the Platform - VHL, using the databases (LILACS), (BDENF), 
and through Google Scholar Portal, adhering to the descriptors: "Stress", "Nursing Professionals", "Intensive Care Unit", combined with the operator "Boolean". Intensive Care Units demonstrate that nursing professionals who work in these environments face high levels of stress. There is a very close relationship between daily exposure to stressors related to the exhausting and tiring environment and stress. Health professionals, particularly those who work in Intensive Care Units (ICUs), are in a vulnerable situation for the development of stress conditions. In a ICU, the work routine is marked by variability, uncertainty and risk, factors that can trigger stress for many professionals; in addition, excessive noise, the relationship with the team and the relationship with family members and patients can be additional sources of stress in this context. The nurse and the hospital must recognize the stressors that are present at work and look for individual and collective coping mechanisms and strategies to reduce the occurrence of professional stress.

Keywords: Stress; Nursing professionals; Intensive Care Unit.

\section{Resumen}

Analizar la evidencia científica sobre factores de estrés en profesionales de enfermería que laboran en la Unidad de Cuidados Intensivos. Se trata de una revisión bibliográfica del método de revisión integrativa de literatura, realizada en los meses de noviembre y diciembre de 2020. La búsqueda se realizó, a través de la Plataforma - BVS, utilizando las bases de datos (LILACS), (BDENF), y a través de Portal Google Scholar, adhiriéndose a los descriptores: "Estrés", "Profesionales de Enfermería", "Unidad de Cuidados Intensivos", combinado con el operador "Booleano". Las Unidades de Cuidados Intensivos demuestran que los profesionales de enfermería que trabajan en estos entornos enfrentan altos niveles de estrés. Existe una relación muy estrecha entre la exposición diaria a factores estresantes relacionados con el entorno agotador y agotador y el estrés. Los profesionales de la salud, particularmente los que laboran en Unidades de Cuidados Intensivos (UCI), se encuentran en una situación vulnerable para el desarrollo de condiciones de estrés. En una UCI, la rutina laboral está marcada por la variabilidad, la incertidumbre y el riesgo, factores que pueden desencadenar el estrés para muchos profesionales; Además, el ruido excesivo, la relación con el equipo y la relación con familiares y pacientes pueden ser fuentes adicionales de estrés en este contexto. La enfermera y el hospital deben reconocer los factores estresantes presentes en el trabajo y buscar mecanismos y estrategias de afrontamiento individuales y colectivos para reducir la ocurrencia de estrés profesional.

Palabras clave: Estrés; Profesionales de enfermería; Unidad de Terapia Intensiva.

\section{Introdução}

A Unidade de Terapia Intensiva é o ambiente destinado à assistência especializada a indivíduos em situações graves que necessitam de cuidados permanentes. Ambiente com dinâmica complexa, no qual a concentração de recursos humanos e tecnológicos são necessários para o monitoramento contínuo, como também, para intervenções em situações de emergência. É considerada por muitos, como um dos locais mais ofensivos e traumatizantes, tanto para pacientes quanto para profissionais. $\mathrm{O}$ ruído constante, situações de emergência, lidar com o sofrimento e a morte, conflitos interpessoais, dentre outros, são fatores contribuintes a esta estereotipagem (Cabral, Neves, \& Oliveira, 2016).

Na UTI, a rotina de situações emergenciais e a concentração de pacientes críticos com alterações súbitas no estado de saúde torna este local de trabalho estressante e agressivo, gerando, muitas vezes, um ambiente emocionalmente comprometido para a equipe multiprofissional e, principalmente, para a equipe de enfermagem que possui uma rotina diária de pronto atendimento, responsabilização por pacientes graves e mortes frequentes (Rodrigues, 2012).

O trabalho do enfermeiro em UTI reveste-se de características especiais em razão das atividades na assistência direta ao paciente e seus familiares, além das atividades gerenciais e administrativas, que incluem todos os recursos necessários ao funcionamento da unidade. É responsável ainda por atividades com alto grau de dificuldade e responsabilidade, os quais contribuem efetivamente no desenvolvimento de fatores psicossociais que condicionam a presença de estresse no trabalho, englobando o estresse físico, psicológico e moral (Trettene, Costa, Prado, Tabaquim, \& Razera, 2018).

Segundo Gouveia, Torres, Costa e Robazzi (2015), o estresse, é o conjunto de reações do organismo às agressões variadas; é uma resposta de adaptação mediada por características individuais ou processos psicológicos. Pode acontecer no trabalho quando a capacidade de adaptação do trabalhador é suplantada por eventos e sobrecargas emocionais.

O estresse pode ocorrer como uma quebra da homeostase interna, ou seja, a reação do mesmo é eliciada por um estressor que consiste em qualquer evento ou situação do ambiente que quebre a homeostase interna, exigindo um esforço de 
adaptação. Dessa forma, o estresse pode ser dividido em três fases: fase de alerta (considerada a fase positiva - o ser humano se energiza através de produção da adrenalina, onde a sobrevivência é preservada e uma sensação de plenitude é frequentemente alcançada), fase de resistência (a pessoa automaticamente tenta lidar com os seus estressores de modo a manter sua homeostase interna) e fase de exaustão (quando doenças graves podem ocorrer nos órgãos mais vulneráveis, como enfarte, úlceras, depressão, entre outros) (Trettene, Costa, Prado, Tabaquim, \& Razera, 2018).

No contexto da enfermagem, os profissionais quase sempre atuam em meio a riscos e condições desfavoráveis que podem influenciar diretamente na sua saúde física e mental, resultando em estresse e prejuízos ao trabalho. Essa condição ocorre porque as atividades conferidas legalmente ao enfermeiro demandam muita atenção, discernimento e responsabilidade, fazendo com que os fatores psicossociais desencadeados pelas atividades laborais desse profissional condicionem o aparecimento do estresse no trabalho (Inouei, Versa, Murassaki, Melo, \& Matsuda, 2013).

O ambiente da UTI gera um estresse na enfermagem por diversos fatores. Dentre eles destacam-se: tecnologia de equipamentos; volume dos alarmes; isolamento das outras clínicas; ambiente insalubre; luz artificial; ambiente frio; número reduzido de funcionários capacitados; rotatividade; sobrecarga de trabalho; baixos salários; o contato muito próximo com os pacientes, mobilizando emoções e conflitos inconscientes tornam esses trabalhadores particularmente susceptíveis ao sofrimento psíquico e ao adoecimento devido ao trabalho. O profissional de enfermagem em uma UTI é indispensável, o enfermeiro desenvolve atividades gerenciais e assistenciais, assumindo responsabilidades mais complexas e que envolvam maior risco para pacientes (Souza et al., 2012).

Diante da problemática em discussão, surge como questão norteadora do estudo: "Quais os fatores de estresse em profissionais de enfermagem que atuam na unidade de terapia intensiva"?

A realização do estudo relacionado à temática, é essencial para a construção do conhecimento, pois, o estudo possibilita a sociedade acadêmica e cientifica a ampliar o conhecimento sobre os fatores geradores de estresse em profissionais de enfermagem que atuam na Unidade de Terapia Intensiva. Desse modo, o estudo trará contribuições importantes para a comunidade científica e para a sociedade, na medida em que acrescentará as evidências científicas discussões relevantes a respeito dessa temática.

Assim, o objetivo do estudo é analisar as evidências científicas sobre os fatores de estresse em profissionais de enfermagem que atuam na Unidade de Terapia Intensiva.

\section{Metodologia}

O presente estudo trata de uma revisão bibliográfica do método revisão integrativa da literatura, realizado nos meses de novembro e dezembro de 2020. Sendo uma ferramenta de investigação que permite à procura, a avaliação crítica e a síntese das evidências disponíveis sobre o tema investigado, em que o produto final é o estado do conhecimento, a implementação de intervenções efetivas na prestação de cuidados e na redução de custos. Além disso, permite a identificação de fragilidades, que poderão conduzir ao desenvolvimento de futuras investigações (Sousa, Marques-Vieira, Severino, \& Antunes, 2017).

A revisão configura-se, portanto, como um tipo de revisão da literatura que reúne achados de estudos desenvolvidos mediante diferentes metodologias, permitindo aos revisores sintetizar resultados sem ferir a filiação epistemológica dos estudos empíricos incluídos. Para que esse processo concretize-se de maneira lógica, isenta de desatinos epistemológicos, a revisão requer que os revisores procedam à análise e à síntese dos dados primários de forma sistemática e rigorosa. Esse instrumento de estudo requer um padrão de excelência quanto ao rigor metodológico para que seu produto possa trazer contribuições significativas para a ciência e para a prática clínica. A preservação deste padrão requer o uso de métodos que garantam a análise precisa, objetiva e completa do tema revisado; o suporte teórico para analisar resultados, métodos, sujeitos e variáveis 
dos estudos primários; a provisão de todas as informações contidas nos estudos revisados e não apenas os principais resultados, de modo a informar o leitor sem o sobrecarregar com informações desnecessárias (Soares et al., 2014)

O processo de revisão da literatura requer a elaboração de uma síntese pautada em diferentes tópicos, capazes de criar uma ampla compreensão sobre o conhecimento. A revisão da literatura é um primeiro passo para a construção do conhecimento científico, pois é através desse processo que novas teorias surgem, bem como são reconhecidas lacunas e oportunidades para o surgimento de pesquisas num assunto específico (Botelho, Cunha, \& Macedo, 2011).

A revisão integrativa permite que o leitor reconheça os profissionais que mais investigam determinado assunto, separar o achado científico de opiniões e ideias, além de descrever o conhecimento no seu estado atual, promovendo impacto sobre a prática clínica. Este método de pesquisa proporciona aos profissionais de saúde dados relevantes de um determinado assunto, em diferentes lugares e momentos, mantendo-os atualizados e facilitando as mudanças na prática clínica como consequência da pesquisa. Dessa forma, acredita-se que a revisão integrativa é uma ferramenta importante no processo de comunicação dos resultados de pesquisas, facilitando a utilização desses na prática clínica, uma vez que proporciona uma síntese do conhecimento já produzido e fornece subsídios para a melhoria da assistência à saúde (Mendes, Silveira, \& Galvão, 2008).

Fluxograma 1. Fases distintas da revisão integrativa.

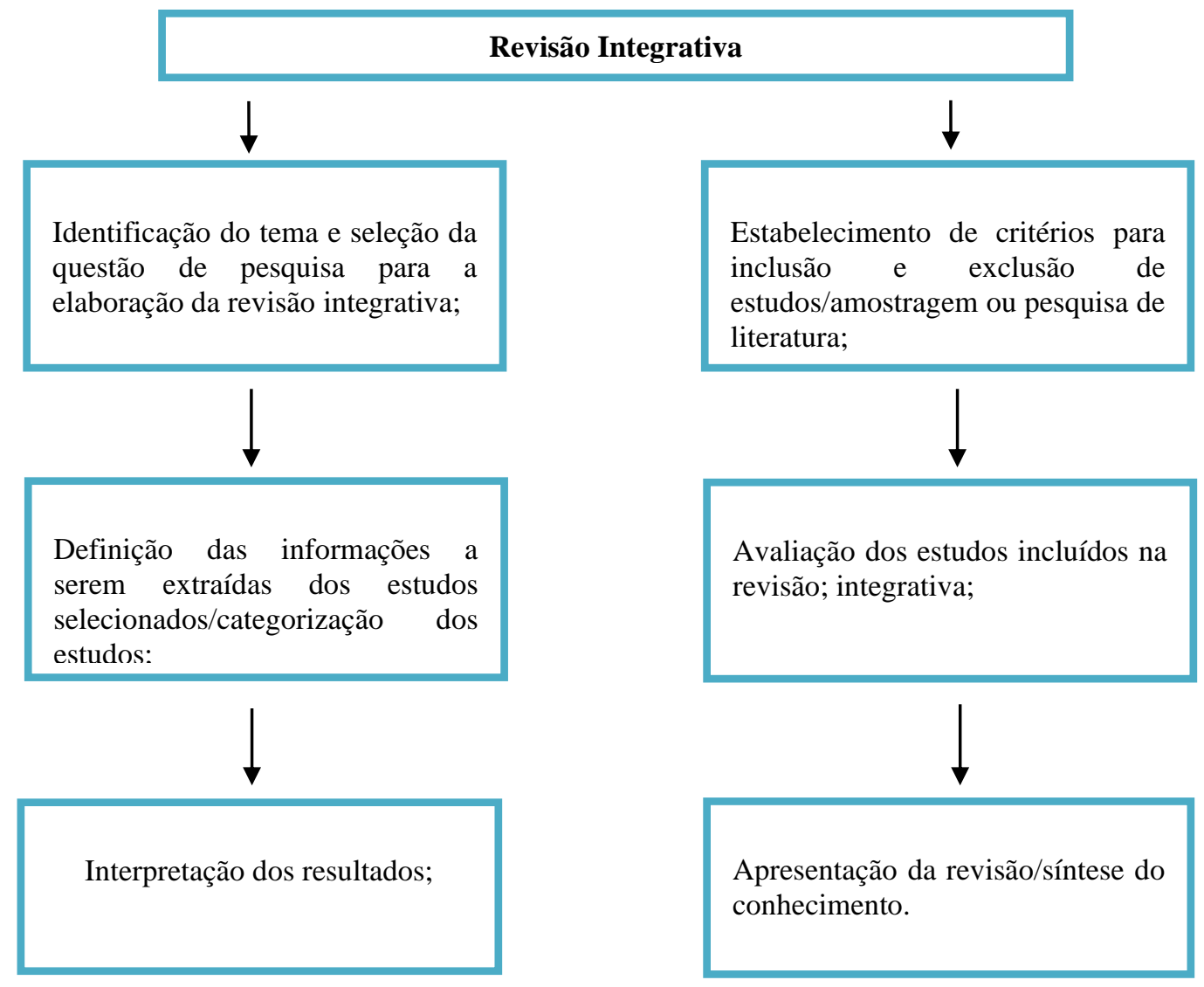

Fonte: Mendes, Silveira, \& Galvão (2008).

A revisão integrativa é um tipo de pesquisa que fornece informações mais amplas de maneira sistemática, ordenada e abrangente, sobre um assunto ou tema, com a finalidade de sintetizar resultados obtidos em pesquisa sobre temas ou questões. A definição das informações a serem extraídas dos estudos selecionados por categorização; avaliação dos estudos incluídos; interpretação dos resultados; e apresentação da revisão/síntese do conhecimento (Ercole, Melo, \& Alcoforado, 2015). 
Estudo elaborado com abordagem qualitativa tornando-se importante a interpretação por parte do pesquisador com suas opiniões sobre o fenômeno em estudo. Neste tipo de pesquisa destacam-se algumas características como: a pesquisa qualitativa, em geral, ocorre no ambiente natural com coleta direta de dados e o pesquisador é o principal instrumento; os dados coletados são preferencialmente descritivos; a preocupação do processo é predominante em relação à do produto; a análise de dados e informações tende a seguir um processo indutivo (Pereira, Shitsuka, Parreira, \& Shitsuka, 2018).

De acordo com Souza, Silva, e Carvalho (2010), a ser realizada nas seguintes etapas: 1- Elaboração da pergunta norteadora; 2- Busca nas bases de dados e amostragem; 3- Coleta de dados, 4- Análise crítica.

Para responder à questão norteadora do estudo: "Quais os fatores de estresse em profissionais de enfermagem que atuam na Unidade de Terapia Intensiva"? aplicou-se os descritores/palavras chaves: "Estresse", "Profissionais de Enfermagem", "Unidade de Terapia Intensiva"

A busca efetuou-se, através da Plataforma da Biblioteca Virtual em Saúde - BVS, utilizando as bases de dados Literatura Latino-Americana e do Caribe em Ciências da Saúde (LILACS), Base de Dados de Enfermagem (BDENF), e por meio do Portal Google Acadêmico, aderindo-se através dos descritores: "Estresse", "Profissionais de Enfermagem", "Unidade de Terapia Intensiva", cruzados com o operador booleando "AND”.

Os critérios de inclusão estabelecidos foram: artigos originais disponibilizados na íntegra, completos, que abrangessem a temática e na forma online, publicados nos idioma português, inglês e espanhol. Os critérios de exclusão estabelecidos na seleção foram: artigos incompletos, artigos duplicados, teses, dissertações, monografias e manuais. No início da pesquisa obteve-se 22944 publicações, após a aplicação dos critérios de inclusão e exclusão totalizou-se parcialmente 1529 artigos, depois de uma leitura mais precisa aderiu-se um total final de 25 publicações de acordo para serem trabalhadas no estudo.

Quadro 1. Seleção de artigos para amostra. Teresina-PI, Brasil, 2020.

\begin{tabular}{|c|c|c|c|}
\hline Bases de dados & Amostra inicial & Amostra parcial & Amostra Final \\
\hline LILACS & 81 & 52 & 10 \\
\hline BDENF & 63 & 47 & 11 \\
\hline GOOGLE ACADÊMICO & 22800 & 1430 & $\mathbf{2 5}$ \\
\hline
\end{tabular}

Fonte: Dados da pesquisa (2020). 
Fluxograma 2. Estratégia de Busca. Teresina-PI, Brasil, 2020.

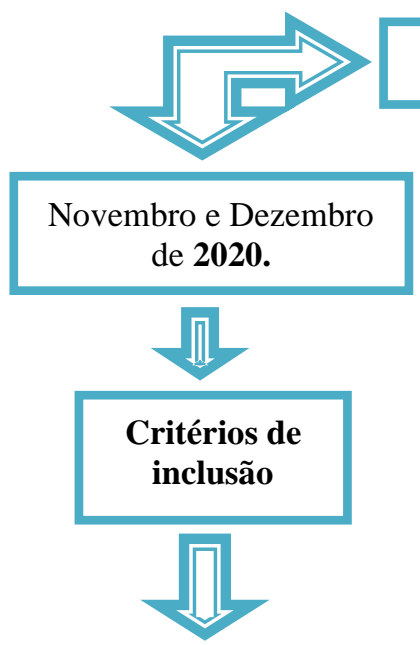

Artigos originais disponibilizados na íntegra, completos, que abrangessem a temática e na forma online, publicados nos idioma português, inglês e espanhol.

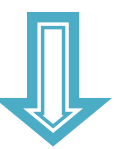

\section{Critérios de exclusão}

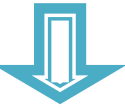

Artigos incompletos, artigos duplicados, teses, dissertações, monografias e manuais.
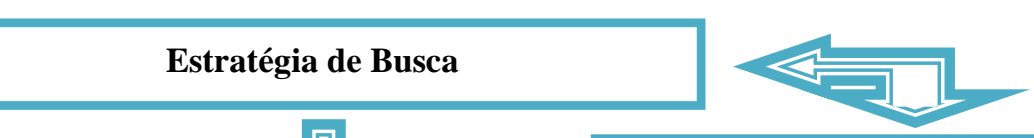

Descritores/Palavras chaves:

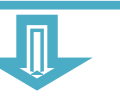

"Estresse", "Profissionais de Enfermagem", "Unidade de

Terapia Intensiva".

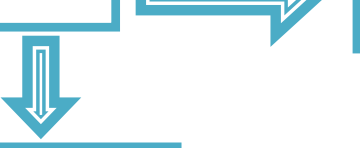

Bases de dados
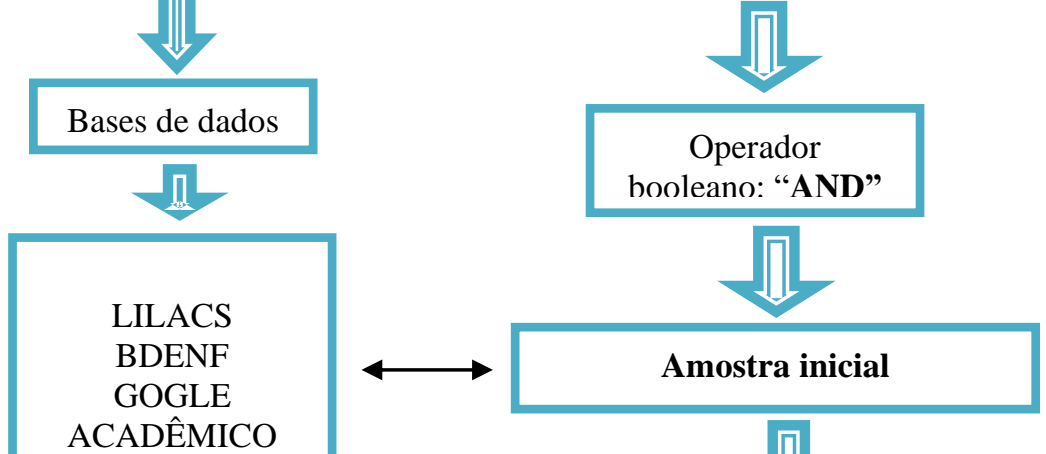

GOGLE ACADÊMICO

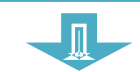

mostra parcial

22944
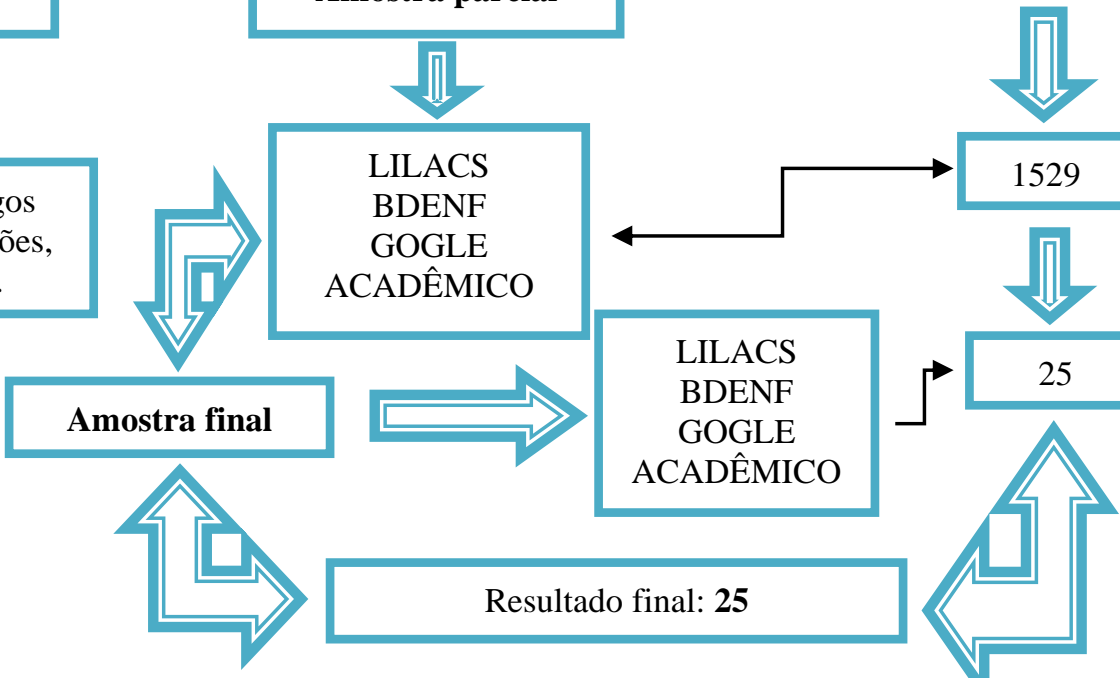

Resultado final: $\mathbf{2 5}$

Fonte: Dados da pesquisa (2020).

No Fluxograma 2, estão expostos estratégia de busca, bases de dados, período de realização do estudo, critérios de inclusão e exclusão, amostra inicial, parcial e final, de acordo com a quantidade de artigos que irão compor os resultados do estudo.

O presente estudo assegura os aspectos éticos, garantindo a autoria dos artigos pesquisados, utilizando para as citações e referências dos autores as normas APA. Os preceitos éticos estabelecidos no que se refere a zelar pela legitimidade das informações, privacidade e sigilo das informações, quando necessárias, tornando os resultados desta pesquisa públicos. Os pesquisadores buscaram a legitimidade e fidelidade nas citações dos autores seja nas citações diretas ou parafraseadas no estudo. 


\section{Resultados e Discussão}

Diante dos resultados obtidos no estudo por meio da estratégia de busca, os autores delinearam variáveis para melhor descrever as evidências encontradas na pesquisa. O quadro a seguir caracteriza os artigos com base nas variáveis propostas: número do artigo, periódico, bases de dados, autor e ano de publicação, título, objetivo, resultados em evidências e conclusões importantes.

Quadro 2 - Artigos selecionados para o estudo.

\begin{tabular}{|c|c|c|c|c|c|c|}
\hline $\mathbf{N}$ & $\begin{array}{l}\text { Periódic } \\
\quad \text { o }\end{array}$ & $\begin{array}{c}\text { Base } \\
\text { de } \\
\text { dados }\end{array}$ & Título & $\begin{array}{l}\text { Autor } \\
\text { e ano }\end{array}$ & Objetivo & $\begin{array}{c}\text { Resultados em evidências e } \\
\text { Conclusões importantes }\end{array}$ \\
\hline 1 & $\begin{array}{c}\text { Rev } \\
\text { Enferm } \\
\text { UFPE } \\
\text { Online. }\end{array}$ & BDENF & $\begin{array}{l}\text { Níveis de estresse } \\
\text { da enfermagem } \\
\text { nas Unidades de } \\
\text { Terapia Intensiva. }\end{array}$ & $\begin{array}{l}\text { Moura et } \\
\text { al., } 2019 .\end{array}$ & $\begin{array}{l}\text { Descrever os níveis de estresse } \\
\text { entre os profissionais de } \\
\text { Enfermagem de nível médio nas } \\
\text { unidades de terapia intensiva } \\
\text { adulto de alguns serviços } \\
\text { hospitalares privados. }\end{array}$ & $\begin{array}{l}\text { Tem-se o estresse ocupacional, como } \\
\text { característica, o conjunto de fenômenos } \\
\text { subjetivos vivenciados internamente e } \\
\text { externamente, de modo individual e distinto } \\
\text { frente aos estressores no ambiente laboral, } \\
\text { sendo o efeito da influência mútua e excessiva } \\
\text { do trabalho e dos recursos impostos, em longo } \\
\text { prazo, capaz de resultar na alteração da } \\
\text { psicofisiologia do trabalhador, propiciando o } \\
\text { elevado índice de absenteísmo que onera o } \\
\text { Estado, o trabalhador e o empregador. }\end{array}$ \\
\hline 2 & $\begin{array}{c}\text { J. Res.: } \\
\text { Fundam. } \\
\text { Care. } \\
\text { Online. }\end{array}$ & LILACS & \begin{tabular}{lr} 
O nível de \\
estresse & dos \\
enfermeiros & na \\
Unidade & de \\
\multicolumn{2}{l}{ Terapia Intensiva. }
\end{tabular} & $\begin{array}{l}\text { Zavalis et } \\
\text { al., } 2019 .\end{array}$ & $\begin{array}{l}\text { Verificar o nível de estresse nos } \\
\text { enfermeiros que atuam em } \\
\text { unidade de terapia intensiva e } \\
\text { identificar as atividades do } \\
\text { trabalho que são mais } \\
\text { estressantes. }\end{array}$ & $\begin{array}{l}\text { Ao se considerar que os efeitos do estresse sob } \\
\text { o indivíduo estão diretamente relacionados ao } \\
\text { tempo de exposição e intensidade dos fatores } \\
\text { estressores, verifica-se que a cronicidade do } \\
\text { estado de estresse pode diminuir as funções } \\
\text { cognitivas do indivíduo e, aliado a constantes } \\
\text { eventos cotidianos, causam irritação, além de } \\
\text { influenciar negativamente os processos } \\
\text { assistenciais, a memória e a atenção. }\end{array}$ \\
\hline 3 & $\begin{array}{l}\text { Rev } \\
\text { Enferm } \\
\text { UERJ. }\end{array}$ & LILACS & $\begin{array}{l}\text { Estresse } \\
\text { realidade } \\
\text { vivenciada por } \\
\text { enfermeiros } \\
\text { atuantes em um } \\
\text { Centro de Terapia } \\
\text { Intensiva. }\end{array}$ & $\begin{array}{c}\text { Trettene, } \\
\text { Costa, } \\
\text { Prado, } \\
\text { Tabaqui } \\
\text { m, \& } \\
\text { Razera, } \\
2018 .\end{array}$ & $\begin{array}{l}\text { Investigar o nível de estresse em } \\
\text { enfermeiros de um centro de } \\
\text { terapia intensiva. }\end{array}$ & $\begin{array}{l}\text { O enfrentamento de críticas, crises entre } \\
\text { chefias, subordinados e colegas, dificuldades } \\
\text { nas tomadas de decisões, discrepâncias entre as } \\
\text { tarefas, falta de reconhecimento profissional e } \\
\text { dificuldades relacionadas à assistência ao } \\
\text { paciente e sua família, são apontados como } \\
\text { fatores estressantes mais incidentes. As cargas } \\
\text { psíquicas estão relacionadas ao objeto de } \\
\text { trabalho humano, que demanda situações } \\
\text { geradoras de estresse, sofrimento, fadiga, } \\
\text { tensão, e também às formas de organização } \\
\text { desse trabalho, marcado pela rotina, pela falta } \\
\text { de autonomia e pelas formas de supervisão e } \\
\text { controle. }\end{array}$ \\
\hline 4 & Rev Cuid. & LILACS & $\begin{array}{l}\text { Qualidade de vida } \\
\text { dos profissionais } \\
\text { de enfermagem } \\
\text { atuan-tes em } \\
\text { setores críticos. }\end{array}$ & $\begin{array}{c}\text { Souza et } \\
\text { al., } 2018 .\end{array}$ & $\begin{array}{l}\text { Analisar a qualidade de vida de } \\
\text { profissionais de enfermagem } \\
\text { atuantes em setores críticos. }\end{array}$ & $\begin{array}{l}\text { Os profissionais de enfermagem possuem uma } \\
\text { qualidade de vida satisfatória, entretanto, } \\
\text { questões relacionadas à saúde física e a } \\
\text { estrutura da instituição ainda se apresentam } \\
\text { como fatores que interferem na qualidade de } \\
\text { vida dos trabalhadores. }\end{array}$ \\
\hline 5 & $\begin{array}{c}\text { Revista } \\
\text { Interinstituc } \\
\text { io-nal de } \\
\text { Psicologia. }\end{array}$ & LILACS & $\begin{array}{l}\text { Estresse } \\
\text { Profissionais de } \\
\text { Enfermagem: } \\
\text { Importância da } \\
\text { Variável Clima } \\
\text { Organizacional. }\end{array}$ & $\begin{array}{l}\text { Mello, } \\
\text { Reis, \& } \\
\text { Ramos, } \\
2018 .\end{array}$ & $\begin{array}{l}\text { Identificar a vulnerabilidade ao } \\
\text { estresse e a presença de sintomas } \\
\text { de estresse em uma amostra não } \\
\text { probabilística por acessibilidade } \\
\text { composta por } 30 \text { profissionais. }\end{array}$ & $\begin{array}{l}\text { A capacidade de enfrentamento do estresse } \\
\text { varia ao longo do tempo, de acordo com o } \\
\text { nível de desenvolvimento do sujeito, e pode ser } \\
\text { modificada em função da alteração nas } \\
\text { demandas do contexto. A implantação de } \\
\text { programas de intervenção psicológica, visando } \\
\text { à promoção de estratégias de enfrentamento do } \\
\text { estresse e com foco na saúde do trabalhador, } \\
\text { pode auxiliar os enfermeiros a enfrentarem a } \\
\text { vulnerabilidade ao estresse presente em } \\
\text { ambientes de UTI, de forma geral. }\end{array}$ \\
\hline
\end{tabular}




\begin{tabular}{|c|c|c|c|c|c|c|}
\hline 6 & $\begin{array}{l}\text { Rev Bras } \\
\quad \text { Ter } \\
\text { Intensiva. }\end{array}$ & LILACS & $\begin{array}{l}\text { Fatores } \\
\text { psicossoci-ais } \mathrm{e} \\
\text { prevalência da } \\
\text { síndrome de } \\
\text { burnout entre } \\
\text { trabalhadores de } \\
\text { enfermagem } \\
\text { intensivistas. }\end{array}$ & $\begin{array}{r}\text { Silva } e t \\
\text { al., } 2015 .\end{array}$ & $\begin{array}{l}\text { Descrever a prevalência da } \\
\text { síndrome de burnout entre } \\
\text { trabalhadores de enfermagem de } \\
\text { unidades de terapia intensiva, } \\
\text { fazendo associação a aspectos } \\
\text { psicossociais. }\end{array}$ & $\begin{array}{l}\text { Os principais fatores que desencadeiam o } \\
\text { estresse no ambiente laboral estão relacionados } \\
\text { a aspectos da organização, administração, } \\
\text { sistema de trabalho e das relações interpessoais } \\
\text { - fatores que compõem os aspetos } \\
\text { psicossociais. }\end{array}$ \\
\hline 7 & $\begin{array}{l}\text { Rev } \\
\text { Enferm } \\
\text { UFPE } \\
\text { Online. }\end{array}$ & BDENF & $\begin{array}{l}\text { Avaliação do } \\
\text { estresse e } \\
\text { sintomas } \\
\text { apresentados } \\
\text { pelos enfermeiros } \\
\text { de unidades de } \\
\text { terapia intensiva } \\
\text { pediátricas }\end{array}$ & $\begin{array}{l}\text { Gouveia, } \\
\text { Torres, } \\
\text { Costa, \& } \\
\text { Robazzi, } \\
2015 .\end{array}$ & $\begin{array}{l}\text { Avaliar a relação entre o estresse } \\
\text { e os sintomas apresentados pelos } \\
\text { enfermeiros que atuam em UTI's } \\
\text { pediátricas. }\end{array}$ & $\begin{array}{l}\text { Dentre os fatores predisponentes ao estresse, } \\
\text { destacaram-se a baixa remuneração, os ruídos } \\
\text { constantes nas unidades, o convívio com } \\
\text { pacientes em estado terminal e a sobrecarga de } \\
\text { trabalho, estressores condizentes com a } \\
\text { especificidade do setor pesquisado. Em relação } \\
\text { aos sintomas, destacam-se as alterações } \\
\text { músculo-esqueléticas e alterações de sono. }\end{array}$ \\
\hline 8 & $\begin{array}{c}\text { Rev Bras } \\
\text { Enferm. }\end{array}$ & LILACS & $\begin{array}{l}\text { Estresse } \\
\text { ocupacional em } \\
\text { enfermeiros } \\
\text { intensivistas que } \\
\text { prestam cuidados } \\
\text { diretos ao paciente } \\
\text { crítico. }\end{array}$ & $\begin{array}{l}\text { Inoue, } \\
\text { Versa, } \\
\text { Murassak } \\
\text { i, Melo, } \\
\quad \& \\
\text { Matsuda, } \\
2013 \text {. }\end{array}$ & $\begin{array}{l}\text { Identificar o nível de estresse em } \\
\text { enfermeiros intensivistas que } \\
\text { prestam cuidados diretos a } \\
\text { pacientes críticos. }\end{array}$ & $\begin{array}{l}\text { No contexto da enfermagem, os enfermeiros } \\
\text { quase sempre atuam em meio a riscos e } \\
\text { condições desfavoráveis que podem influenciar } \\
\text { diretamente na sua saúde física e mental, } \\
\text { resultando em estresse e prejuízos ao trabalho. } \\
\text { Essa condição ocorre porque as atividades } \\
\text { conferidas legalmente ao enfermeiro } \\
\text { demandam muita atenção, discernimento e } \\
\text { responsabilidade, fazendo com que os fatores } \\
\text { psicossociais desencadeados pelas atividades } \\
\text { laborais desse profissional condicionem o } \\
\text { aparecimento do estresse no trabalho. }\end{array}$ \\
\hline 9 & $\begin{array}{l}\text { Acta Paul } \\
\text { Enferm. }\end{array}$ & LILACS & $\begin{array}{l}\text { Estresse dos } \\
\text { profissionais } \\
\text { enfer-meiros que } \\
\text { atuam na unidade } \\
\text { de terapia } \\
\text { intensiva. }\end{array}$ & $\begin{array}{l}\text { Monte, } \\
\text { Lima, } \\
\text { Neves, } \\
\text { Studart, } \\
\quad \& \\
\text { Dantas, } \\
2013 \text {. }\end{array}$ & $\begin{array}{l}\text { Avaliar o estresse no ambiente de } \\
\text { trabalho dos profissionais } \\
\text { enfermeiros dentro das Unidades } \\
\text { de Terapia Intensiva e identificar } \\
\text { os agentes estressores associados } \\
\text { ao desencadeamento do estresse } \\
\text { segundo a Escala Bianchi de } \\
\text { Estresse. }\end{array}$ & $\begin{array}{l}\text { O enfermeiro é um profissional com condições } \\
\text { estressantes de trabalho e presta assistência em } \\
\text { setores considerados desgastantes como a } \\
\text { unidade de terapia intensiva, tanto pela carga } \\
\text { de trabalho como pela especificidade das } \\
\text { tarefas. Existe a constante presença de óbitos, } \\
\text { frequentes situações de emergência, controle } \\
\text { de material utilizado e equipamentos, atender } \\
\text { as necessidades dos familiares, realizar } \\
\text { atividades com tempo mínimo disponível, falta } \\
\text { de pessoal e material, ruído constante dos } \\
\text { aparelhos, o sofrimento e angústiados } \\
\text { familiares. }\end{array}$ \\
\hline 10 & $\begin{array}{l}\text { Psicologia } \\
\text { Ciência e } \\
\text { Profissão. }\end{array}$ & LILACS & $\begin{array}{lr}\text { Adoecimento Psí- } \\
\text { quico } & \text { de } \\
\text { Trabalhadores } & \text { de } \\
\text { Unidades } & \text { de } \\
\text { Terapia Intensiva. }\end{array}$ & $\begin{array}{l}\text { Monteiro } \\
\text { Oliveira, } \\
\text { Ribeiro, } \\
\text { Grisa, \& } \\
\text { Agostini, } \\
2013 \text {. }\end{array}$ & \begin{tabular}{lrr} 
Compreender & \multicolumn{2}{c}{ os aspectos } \\
relacionados à & organização do \\
trabalho que & possam estar \\
contribuindo & para & o \\
desenvolvimento & de \\
psicopatologias (depressão e/ou \\
burnout) no trabalhador de saúde \\
em unidade de terapia intensiva \\
bem como descrever as \\
estratégias defensivas utilizadas \\
pelos trabalhadores para lidar \\
com às dificuldades vivenciadas \\
nesse contexto de trabalho.
\end{tabular} & $\begin{array}{l}\text { Os profissionais que trabalham em ambientes } \\
\text { considerados críticos, como as unidades de } \\
\text { tratamento intensivo (UTI), apresentam alta } \\
\text { predisposição para serem acometidos pelo } \\
\text { sofrimento psíquico, tendo em vista a } \\
\text { complexidade das ações ali realizadas, o } \\
\text { estresse gerado durante a sua realização e a } \\
\text { ocorrência de morte de pacientes. }\end{array}$ \\
\hline 11 & $\begin{array}{l}\text { Rev } \\
\text { Gaúcha } \\
\text { Enferm. }\end{array}$ & BDENF & $\begin{array}{l}\text { Estresse ocupacio- } \\
\text { nal: avaliação de } \\
\text { enfermeiros } \\
\text { intensi-vistas que } \\
\text { atuam no período } \\
\text { noturno. }\end{array}$ & $\begin{array}{c}\text { Versa } e t \\
\text { al., } 2012 .\end{array}$ & $\begin{array}{l}\text { Avaliar o nível de estresse de } \\
\text { enfermeiros intensivistas do } \\
\text { período noturno. }\end{array}$ & $\begin{array}{l}\text { Um fator relacionado às condições de trabalho } \\
\text { seja em instituição pública ou privada, consiste } \\
\text { na atuação noturna, pois esse período de } \\
\text { trabalho expõe os profissionais a alguns danos } \\
\text { à saúde. Em estudos acerca do estresse e } \\
\text { qualidade do sono entre enfermeiros de } \\
\text { diferentes turnos constatou-se que as } \\
\text { características dos setores críticos e da atuação } \\
\text { noturna geram distúrbios físicos e psíquicos, } \\
\text { tais como alterações hormonais e gástricas, } \\
\text { causadas pelos ruídos excessivos do setor, pelo } \\
\text { ambiente fechado e pela privação do sono. }\end{array}$ \\
\hline
\end{tabular}




\begin{tabular}{|c|c|c|c|c|c|c|}
\hline 12 & $\begin{array}{l}\text { R. Pesq.: } \\
\text { Cuid. } \\
\text { Fundam. } \\
\text { Online. }\end{array}$ & BDENF & $\begin{array}{l}\text { O estresse de } \\
\text { enfermeiros } \\
\text { atuantes no } \\
\text { cuidado do adulto } \\
\text { na unidade de } \\
\text { terapia intensiva. }\end{array}$ & $\begin{array}{c}\text { Souza et } \\
\text { al., } 2012 .\end{array}$ & $\begin{array}{l}\text { Descrever os fatores estressantes } \\
\text { que prejudicam a saúde dos } \\
\text { enfermeiros que atuam no } \\
\text { cuidado do adulto nas Unidades } \\
\text { de Terapia Intensiva e possíveis } \\
\text { medidas para reduzir esses } \\
\text { estresses apontados pela } \\
\text { literatura. }\end{array}$ & $\begin{array}{l}\text { Diante dos fatores estressores serem } \\
\text { destacados de forma similar entre diversas } \\
\text { regiões, pode-se concluir que independente do } \\
\text { tipo de Instituição, seja privada ou pública, os } \\
\text { sentimentos e o ambiente vivenciados pelos } \\
\text { profissionais de saúde são praticamente iguais, } \\
\text { ressaltando, portanto que os enfermeiros, por } \\
\text { ser um elo entre os outros funcionários, têm a } \\
\text { responsabilidade de reconhecer estes fatores } \\
\text { estressantes. }\end{array}$ \\
\hline 13 & $\begin{array}{l}\text { Rev Esc } \\
\text { Enferm } \\
\text { USP. }\end{array}$ & LILACS & $\begin{array}{lr}\text { O estresse } & \text { entre } \\
\text { enfermeiros } & \text { que } \\
\text { atuam } & \text { em } \\
\text { Unidade } & \text { de } \\
\text { Terapia Intensiva. }\end{array}$ & $\begin{array}{l}\text { Preto, \& } \\
\text { Pedrão, } \\
2009 .\end{array}$ & $\begin{array}{l}\text { Caracterizar os enfermeiros que } \\
\text { atuam em UTI e verificar a } \\
\text { presença de estresse entre eles. }\end{array}$ & $\begin{array}{l}\text { A enfermagem é uma profissão estressante e } \\
\text { esse fato se relaciona ao trabalho com pessoas } \\
\text { que sofrem e requerem grande demanda de } \\
\text { atenção, compaixão e simpatia. O enfermeiro } \\
\text { quando lida com essa situação pode se sentir } \\
\text { irritado, deprimido e desapontado. Esses } \\
\text { sentimentos podem ser considerados } \\
\text { incompatíveis, com o desempenho } \\
\text { profissional, trazendo consequentemente a } \\
\text { culpa e o aumento da ansiedade. }\end{array}$ \\
\hline 14 & $\begin{array}{l}\text { Rev Esc } \\
\text { Enferm } \\
\text { USP. }\end{array}$ & LILACS & \begin{tabular}{lr}
\multicolumn{2}{l}{ Caracterização do } \\
estresse & nos \\
enfermeiros & de \\
unidades & de \\
terapia intensiva.
\end{tabular} & $\begin{array}{l}\text { Guerrer, } \\
\& \\
\text { Bianchi, } \\
2008 .\end{array}$ & $\begin{array}{l}\text { Caracterizar a população de } \\
\text { enfermeiros que atuam em UTI } \\
\text { no Brasil e associar o nível de } \\
\text { estresse relatado pelos } \\
\text { enfermeiros com idade, cargo } \\
\text { ocupado, tempo de formado e } \\
\text { frequência a cursos de pós- } \\
\text { graduação. }\end{array}$ & $\begin{array}{l}\text { O enfermeiro e a instituição hospitalar devem } \\
\text { reconhecer os estressores que estão presentes } \\
\text { no trabalho e procurar mecanismos e } \\
\text { estratégias de enfrentamento individual e } \\
\text { grupal para diminuir a ocorrência de estresse } \\
\text { profissional. }\end{array}$ \\
\hline 15 & $\begin{array}{l}\text { Rev. Cient. } \\
\text { Sena Aires. }\end{array}$ & $\begin{array}{l}\text { GOOGL } \\
\text { E } \\
\text { ACADÊ } \\
\text { MICO }\end{array}$ & $\begin{array}{l}\text { Estresse e burnout } \\
\text { em profissionais } \\
\text { de enfermagem de } \\
\text { Unidade de } \\
\text { Terapia Intensiva } \\
\text { e semi-intensiva. }\end{array}$ & $\begin{array}{l}\text { Silva1 et } \\
\text { al., } 2018 .\end{array}$ & $\begin{array}{l}\text { Identificar a frequência dos } \\
\text { sintomas de estresse e a } \\
\text { ocorrência de Síndrome de } \\
\text { Burnout em profissionais de } \\
\text { enfermagem que atuam em } \\
\text { unidade de terapia intensiva e } \\
\text { semi-intensiva. }\end{array}$ & $\begin{array}{l}\text { Os sintomas de estresse mais frequentemente } \\
\text { percebidos pelos profissionais de enfermagem } \\
\text { foram: sensação de desgaste, cansaço e } \\
\text { sobrecarga no trabalho. Sabe-se que as } \\
\text { características inerentes ao processo de } \\
\text { trabalho em enfermagem, assim como as } \\
\text { condições de trabalho a que estão expostos, } \\
\text { podem contribuir para o desenvolvimento do } \\
\text { estresse e a manifestação de seus sintomas. }\end{array}$ \\
\hline 16 & REME. & $\begin{array}{l}\text { GOOGL } \\
\text { E } \\
\text { ACADÊ } \\
\text { MICO }\end{array}$ & $\begin{array}{l}\text { Fatores } \\
\text { estressores para a } \\
\text { equipe r de } \\
\text { enfermagem da } \\
\text { unidade de terapia } \\
\text { intensiva. }\end{array}$ & $\begin{array}{l}\text { Rodrigue } \\
\text { s, } 2012 .\end{array}$ & $\begin{array}{l}\text { Investigar, por meio de revisão de } \\
\text { literatura, os fatores que geram } \\
\text { estresse à equipe de enfermagem } \\
\text { na unidade de terapia intensiva. }\end{array}$ & $\begin{array}{l}\text { Os fatores ambientais da UTI podem contribuir } \\
\text { para a evolução dos sintomas de estresse e } \\
\text { influenciar o trabalho dos profissionais de } \\
\text { forma negativa. A iluminação artificial, o } \\
\text { ruído, a temperatura, o ambiente fechado e a } \\
\text { planta física são alguns desses fatores. }\end{array}$ \\
\hline 17 & $\begin{array}{c}\text { Revista } \\
\text { Eletrônica } \\
\text { "Diálogos } \\
\text { Acadêmico } \\
\text { s". }\end{array}$ & $\begin{array}{l}\text { GOOGL } \\
\text { E } \\
\text { ACADÊ } \\
\text { MICO }\end{array}$ & $\begin{array}{lr}\text { Estresse } & \text { dos } \\
\text { profissionais } & \text { de } \\
\text { enfermagem } & \text { em } \\
\text { unidade de terapia } \\
\text { intensiva (UTI). }\end{array}$ & $\begin{array}{l}\text { Cabral, } \\
\text { Neves, \& } \\
\text { Oliveira, } \\
2016 .\end{array}$ & $\begin{array}{l}\text { Avaliar a ocorrência do estresse } \\
\text { nos profissionais de enfermagem } \\
\text { em UTI, por meio da análise dos } \\
\text { fatores desencadeadores, de } \\
\text { manutenção e potencialização dos } \\
\text { seus sintomas, assim como os } \\
\text { aspectos de que evidenciam sua } \\
\text { ocorrência. }\end{array}$ & $\begin{array}{l}\text { A UTI, reconhecidamente como essencial na } \\
\text { recuperação de vidas, tem na enfermagem o } \\
\text { alicerce e os pilares de sustentação do cuidado } \\
\text { integral e ininterrupto. Entretanto, a sobrecarga } \\
\text { de trabalho, a desvalorização salarial e falta de } \\
\text { reconhecimento, fragilizam esta estrutura, uma } \\
\text { vez que, o estresse, distancia o profissional de } \\
\text { suas práticas preventivas, holísticas e } \\
\text { integradoras intrínsecas ao enfermeiro e à } \\
\text { equipe de enfermagem intensivista. }\end{array}$ \\
\hline 18 & $\begin{array}{l}\text { Revista } \\
\text { Científica } \\
\text { Interdiscipli } \\
\quad \text { nar. }\end{array}$ & $\begin{array}{l}\text { GOOGL } \\
\text { E } \\
\text { ACADÊ } \\
\text { MICO }\end{array}$ & $\begin{array}{l}\text { O estresse entre os } \\
\text { profissionais de } \\
\text { enfermagem na } \\
\text { unidade de terapia } \\
\text { intensiva. }\end{array}$ & $\begin{array}{l}\text { Campos, } \\
\text { Oliveira, } \\
\text { Nunes, } \\
2017 .\end{array}$ & $\begin{array}{l}\text { Ressaltar a necessidade de um } \\
\text { olhar diferenciado aos } \\
\text { profissionais de enfermagem, aos } \\
\text { quais estão sujeitos ao } \\
\text { desenvolvimento de elevados } \\
\text { níveis de estresse na Unidade de } \\
\text { Terapia Intensiva. }\end{array}$ & $\begin{array}{l}\text { Uma forma positiva de amenizar o nível de } \\
\text { estresse é quando o serviço flui em harmonia e } \\
\text { a equipe de enfermagem está sintonizada, } \\
\text { podendo assim propiciar mais qualidade de } \\
\text { vida a estes profissionais. Além disso, é } \\
\text { preciso que o profissional reconheça as } \\
\text { manifestações do estresse e aprenda a } \\
\text { identificar os agentes estressores, os quais são, } \\
\text { muitas vezes, acarretados por desmotivação e } \\
\text { insatisfação, levando à diminuição da } \\
\text { produtividade e do estado de alerta. }\end{array}$ \\
\hline
\end{tabular}




\begin{tabular}{|c|c|c|c|c|c|c|}
\hline 19 & $\begin{array}{l}\text { Rev. Acta } \\
\text { de Estudos } \\
\text { Interdiscipli } \\
\text { nares. }\end{array}$ & $\begin{array}{l}\text { GOOGL } \\
\text { E } \\
\text { ACADÊ } \\
\text { MICO }\end{array}$ & $\begin{array}{l}\text { A Unidade de } \\
\text { Terapia Intensiva } \\
\text { um ambiente } \\
\text { estressante para os } \\
\text { profissionais de } \\
\text { enfermagem. }\end{array}$ & $\begin{array}{l}\text { Abrantes, } \\
\text { \& } \\
\text { Carmo, } \\
2020 .\end{array}$ & $\begin{array}{l}\text { Compreender, por meio da } \\
\text { revisão literária, os fatores que } \\
\text { geram estresse na equipe de } \\
\text { enfermagem da Unidade de } \\
\text { Terapia Intensiva. }\end{array}$ & $\begin{array}{l}\text { Os fatores estressantes existentes na unidade } \\
\text { de terapia intensiva que afetam a equipe de } \\
\text { enfermagem, são em grande número e dentre } \\
\text { eles destacam-se: o gerenciamento da unidade, } \\
\text { o nível de barulho que esse setor hospitalar } \\
\text { produz, o enfrentamento da morte do paciente } \\
\text { e a assistência prestada na unidade ao paciente } \\
\text { crítico. }\end{array}$ \\
\hline 20 & $\begin{array}{l}\text { Revista } \\
\text { Brasileira } \\
\text { de Ciências } \\
\text { da Saúde. }\end{array}$ & $\begin{array}{l}\text { GOOGL } \\
\text { E } \\
\text { ACADÊ } \\
\text { MICO }\end{array}$ & $\begin{array}{l}\mathrm{O} \text { Estresse } \mathrm{em} \\
\text { profissionais } \\
\text { enfermagem. }\end{array}$ & $\begin{array}{l}\text { Ratochin } \\
\text { sk, } \\
\text { Powlowy } \\
\text { tsch, } \\
\text { Grzelcza } \\
\text { k, \& } \\
\text { Souza, } \\
2016 .\end{array}$ & 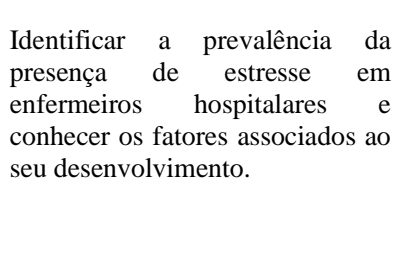 & $\begin{array}{l}\text { A exposição prolongada aos agentes } \\
\text { estressores pode ter como consequência o } \\
\text { baixo desempenho profissional, baixa moral e } \\
\text { baixa autoestima, alta rotatividade, } \\
\text { absenteísmo e violência, prejudicando todo o } \\
\text { trabalho realizado. }\end{array}$ \\
\hline 21 & $\begin{array}{l}\text { Rev. Educ. } \\
\text { Meio Amb. } \\
\text { Saú. }\end{array}$ & $\begin{array}{l}\text { GOOGL } \\
\text { E } \\
\text { ACADÊ } \\
\text { MICO }\end{array}$ & $\begin{array}{l}\text { Estresse } \\
\text { ocupacional em } \\
\text { enfermeiros } \\
\text { atuantes na } \\
\text { unidade de terapia } \\
\text { intensiva. }\end{array}$ & $\begin{array}{l}\text { Fernande } \\
\text { s et al., } \\
2019 .\end{array}$ & $\begin{array}{l}\text { Descrever a presença do estresse } \\
\text { ocupacional no profissional de } \\
\text { enfermagem atuante na Unidade } \\
\text { de Terapia Intensiva. }\end{array}$ & $\begin{array}{l}\text { É necessária a adoção de estratégias voltadas à } \\
\text { prevenção do estresse, por meio dos gestores } \\
\text { institucionais e também de seus trabalhadores. } \\
\text { Assim, terá um ambiente adequado para o } \\
\text { profissional exercer seu trabalho preservando } \\
\text { sua saúde e bem estar. }\end{array}$ \\
\hline 22 & $\begin{array}{l}\text { Revista } \\
\text { JRG de } \\
\text { Estudos } \\
\text { Acadêmico } \\
\text { s. }\end{array}$ & $\begin{array}{l}\text { GOOGL } \\
\text { E } \\
\text { ACADÊ } \\
\text { MICO }\end{array}$ & $\begin{array}{lr}\text { O } & \text { estresse } \\
\text { ocupacional no } \\
\text { enfermeiro que } \\
\text { atua na } & \text { Unidade } \\
\text { de } & \text { Terapia } \\
\text { Intensiva. }\end{array}$ & $\begin{array}{l}\text { Oliveira, } \\
\quad \& \\
\text { Gonçalve } \\
\text { s, } 2019 .\end{array}$ & 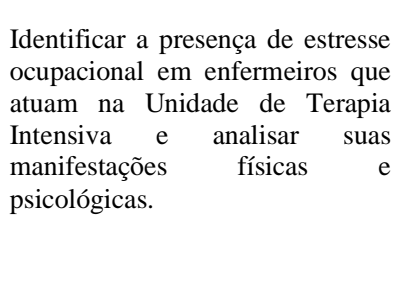 & $\begin{array}{l}\text { Os profissionais que atuam na UTI estão } \\
\text { sujeitos a exigências em vários pontos: } \\
\text { fisicamente, emocionalmente e socialmente, } \\
\text { pois lidam em tempo integral com questões } \\
\text { afetivas, físicas e espirituais dos seus pacientes } \\
\text { e familiares. Os profissionais enfermeiros } \\
\text { possuem carga de trabalho em grande parte } \\
\text { desgastante, que a longo prazo compromete a } \\
\text { qualidade do serviço oferecido. }\end{array}$ \\
\hline 23 & $\begin{array}{c}\text { Revista } \\
\text { Pró- } \\
\text { UniverSUS } \\
\text {. }\end{array}$ & $\begin{array}{l}\text { GOOGL } \\
\text { E } \\
\text { ACADÊ } \\
\text { MICO }\end{array}$ & $\begin{array}{lr}\text { Evidências } & \text { e } \\
\text { repercussões } & \text { do } \\
\text { estresse } & \\
\text { vivenciado } & \text { pelos } \\
\text { enfermeiros } & \text { da } \\
\text { unidade de } & \text { terapia } \\
\text { intensiva: } & \text { um } \\
\text { estudo } & \text { das } \\
\text { publicações } & \\
\text { brasileiras. }\end{array}$ & $\begin{array}{l}\text { Ribeiro } \\
\text { et al., } \\
2019 .\end{array}$ & $\begin{array}{l}\text { Identificar as evidências e } \\
\text { repercussões que acometem o } \\
\text { enfermeiro que atua na UTI e } \\
\text { propor estratégias para } \\
\text { diminuição dos fatores estressores } \\
\text { que acometem o enfermeiro que } \\
\text { atua na UTI. }\end{array}$ & $\begin{array}{l}\text { Nota-se que existem inúmeras situações no } \\
\text { âmbito hospitalar que podem interferir na } \\
\text { atuação do enfermeiro em UTI's, tais como: } \\
\text { ambiente extremamente seco, refrigerado, } \\
\text { fechado e com falta de iluminação natural; } \\
\text { ruídos internos contínuos e intermitentes; inter- } \\
\text { relacionamento constante entre os mesmos } \\
\text { profissionais da equipe, durante o plantão, } \\
\text { assim como a cobrança excessiva de } \\
\text { segurança, respeito e responsabilidade com o } \\
\text { paciente, em sofrimento, dor e com morte } \\
\text { iminente, para a garantia da qualidade da } \\
\text { assistência. }\end{array}$ \\
\hline 24 & $\begin{array}{c}\text { Revista E- } \\
\text { F@tec. }\end{array}$ & $\begin{array}{l}\text { GOOGL } \\
\text { E } \\
\text { ACADÊ } \\
\text { MICO }\end{array}$ & $\begin{array}{lr}\text { O } & \text { Estresse } \\
\text { Ocupacional } & \text { no } \\
\text { Enfermeiro } & \text { na } \\
\text { Unidade } & \text { de } \\
\text { Terapia } & \\
\text { Intensiva } & \end{array}$ & $\begin{array}{l}\text { Campos, } \\
\text { Esteves, } \\
\text { Oliveira, } \\
\text { \& Garcia, } \\
2018 .\end{array}$ & $\begin{array}{l}\text { Identificar os fatores causais do } \\
\text { estresse ocupacional, no } \\
\text { enfermeiro, da Unidade de } \\
\text { Terapia Intensiva de um hospital } \\
\text { de porte médio, em uma cidade } \\
\text { no interior do estado de São } \\
\text { Paulo. }\end{array}$ & $\begin{array}{l}\text { O estresse é uma constante na vida diária, } \\
\text { englobando fatores internos e externos que } \\
\text { afetam o nosso bem-estar físico e mental. } \\
\text { Fatores de estresse externos são encontrados } \\
\text { no ambiente físico e pode incluir trabalho, } \\
\text { família, relacionamentos e outros desafios. } \\
\text { Fatores de estresse internos incluem saúde, } \\
\text { nutrição de um indivíduo e estado emocional; } \\
\text { aqueles influenciar a capacidade do corpo para } \\
\text { responder e lidar com estressores externos. }\end{array}$ \\
\hline 25 & $\begin{array}{l}\text { Investig. } \\
\text { Enferm. } \\
\text { Imagen } \\
\text { Desarr. }\end{array}$ & $\begin{array}{l}\text { GOOGL } \\
\text { E } \\
\text { ACADÊ } \\
\text { MICO }\end{array}$ & $\begin{array}{l}\text { Estresse } \\
\text { ocupacional na } \\
\text { enfermagem } \\
\text { atuante na unidade } \\
\text { de terapia } \\
\text { intensiva. }\end{array}$ & $\begin{array}{l}\text { Teixeira, } \\
\text { Veloso, } \\
\text { Ribeiro, } \\
\text { Oliveira, } \\
\text { \& Cortez, } \\
2017 .\end{array}$ & $\begin{array}{l}\text { Descrever, através da revisão } \\
\text { integrativa, o estresse no trabalho } \\
\text { da enfermagem na UTI, bem } \\
\text { como identificar fatores, sinais e } \\
\text { sintomas associados ao estresse } \\
\text { ocupacional. }\end{array}$ & $\begin{array}{l}\text { O estresse ocupacional pode afetar todo e } \\
\text { qualquer trabalhador, uma vez que todo } \\
\text { trabalho é passível de particularidades } \\
\text { especificas que podem provocar situações } \\
\text { geradoras de estresse. É necessário a } \\
\text { identificação de medidas e técnicas que } \\
\text { minimizem os efeitos do estresse para a } \\
\text { enfermagem que atua na UTI com a finalidade } \\
\text { de garantir o bem-estar desses profissionais } \\
\text { para desempenharem com inteira qualidade } \\
\text { suas funções. }\end{array}$ \\
\hline
\end{tabular}


Fonte: Dados da pesquisa (2020).

No Quadro 1, tem-se a apresentação dos artigos selecionados para o estudo conforme número do artigo, periódico, bases de dados, título, autor e ano, objetivo, resultados em evidências e conclusões importantes, com a finalidade de facilitar o desenvolvimento da discussão. A partir do estudo dos artigos estabeleceram-se discussões relevantes para observações das produções científicas relacionadas à pesquisa.

Gráfico 1. Distribuição dos artigos conforme ano e quantidade.

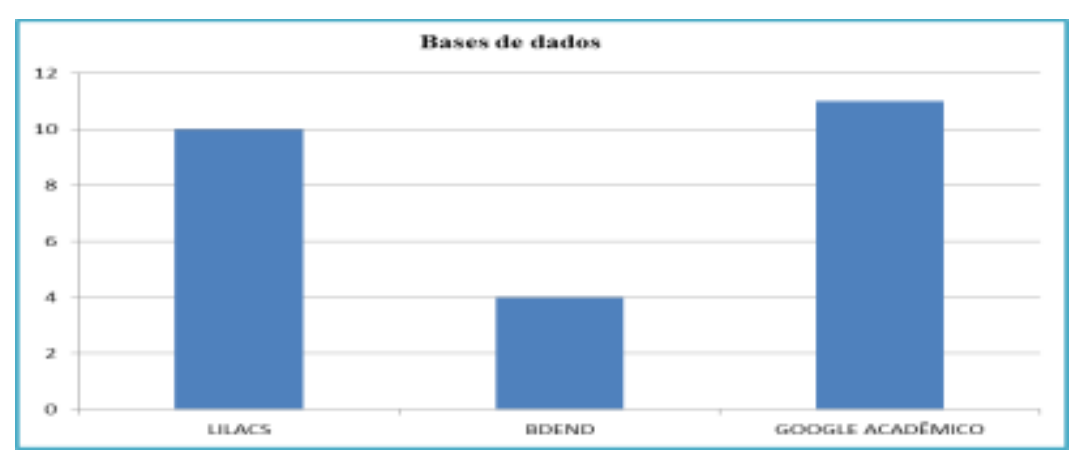

Fonte: Dados da pesquisa (2020).

De acordo com o gráfico acima, percebe-se que estão indexados 10 artigos na base de dados da Literatura Latinoamericana e do Caribe em Ciências da Saúde - LILACS, 4 artigos na Base de Dados de Enfermagem - BDENF, e 11 no Portal Google acadêmico.

Gráfico 2. Distribuição dos artigos conforme base de dados e porcentagem.

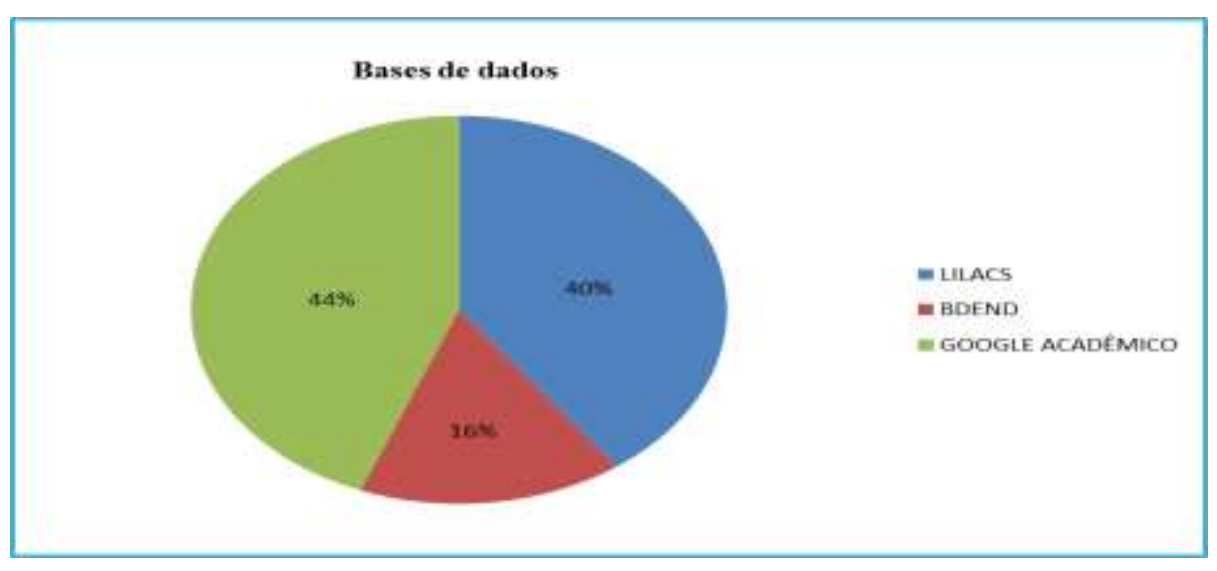

Fonte: Dados da pesquisa (2020).

Ao analisar o gráfico acima, nota-se que $40 \%$ dos artigos que compõem o presente estudo estão indexados na base de dados da Literatura Latino-americana e do Caribe em Ciências da Saúde - LILACS, 16\% na Base de Dados de Enfermagem BDENF, e 44\% no Portal Google acadêmico. 
Gráfico 3. Distribuição dos artigos conforme periódico e quantidade.

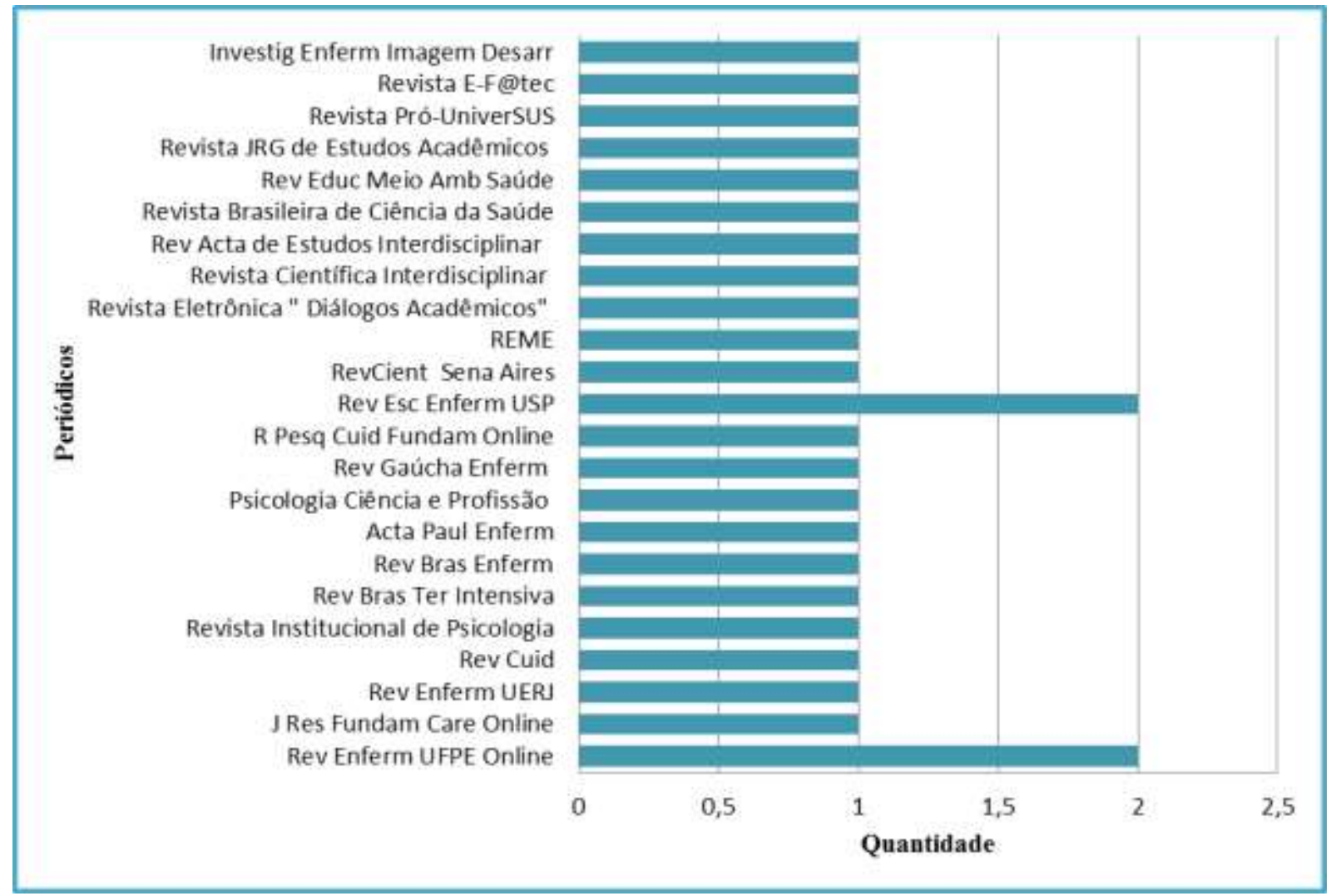

Fonte: Dados da pesquisa (2020).

Segundo o gráfico ilustrado acima, pode-se observar quais são os periódicos e a quantidade de artigos que foram publicados de acordo com a amostra final do referido estudo. A Rev Enferm UFPE Online publicou (2) artigos, J Res Fundam Care Online (1), Rev Enferm UERJ (1), Rev Cuid (1), Revista Institucional de Psicologia (1), Rev Bras Ter Intensiva (1), Rev Rev Enferm UFPE Online (1), Bras Enferm (1), Acta Paul Enferm (1), Psicologia Ciência e Profissão (1), Rev Gaúcha Enferm (1), R Pesq: Cuid Fundam Online (1), Rev Esc Enferm USP (2), Rev Cient Sena Aires (1), REME (1), Revista Eletrônica “Diálogos Acadêmicos” Revista Científica Interdisciplinar (1), Rev Acta de Estudos Interdisciplinar (1), Revista Brasileira de Ciências da Saúde (1), Rev Educ Meio Amb Saúde (1), Revista JRG de Estudos Acadêmicos (1), Revista Pró-UniverSUS (1), e a Revista E-F@ tec (1), Investig Enferm Imagem Desarr (1). 
Gráfico 4. Distribuição dos artigos conforme os anos de publicação e quantidade.

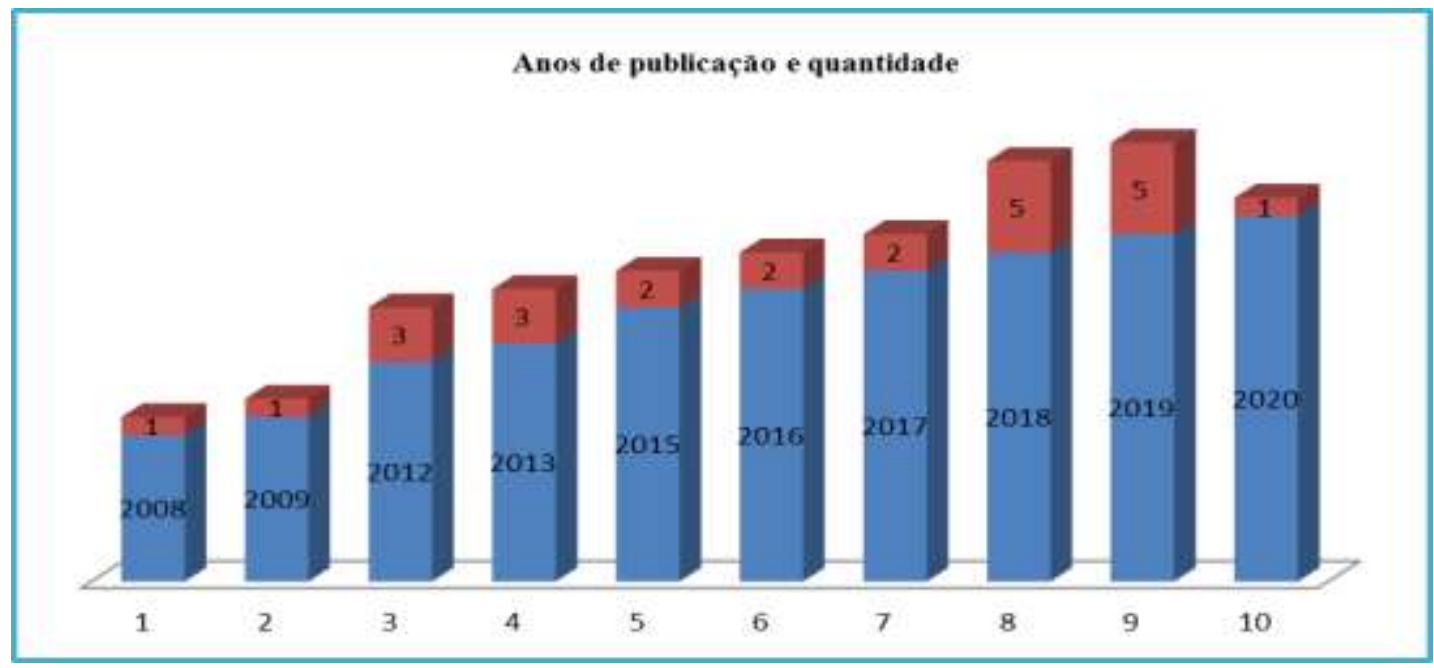

Fonte: Dados da pesquisa (2020).

Verifica-se no gráfico representado acima os anos de publicação e quantidade de artigos publicados, nota-se que no ano de 2008 ocorreu (1) publicação, 2009 (1), 2012 (3), 2013 (3), 2015 (2), 2016 (2), 2017 (2), 2018 (5), 2019 (5), e 2020 (1), totalizando um resultado final de 25 artigos para serem utilizados na construção do presente estudo.

Gráfico 5. Distribuição dos artigos conforme ano de publicação e porcentagem.

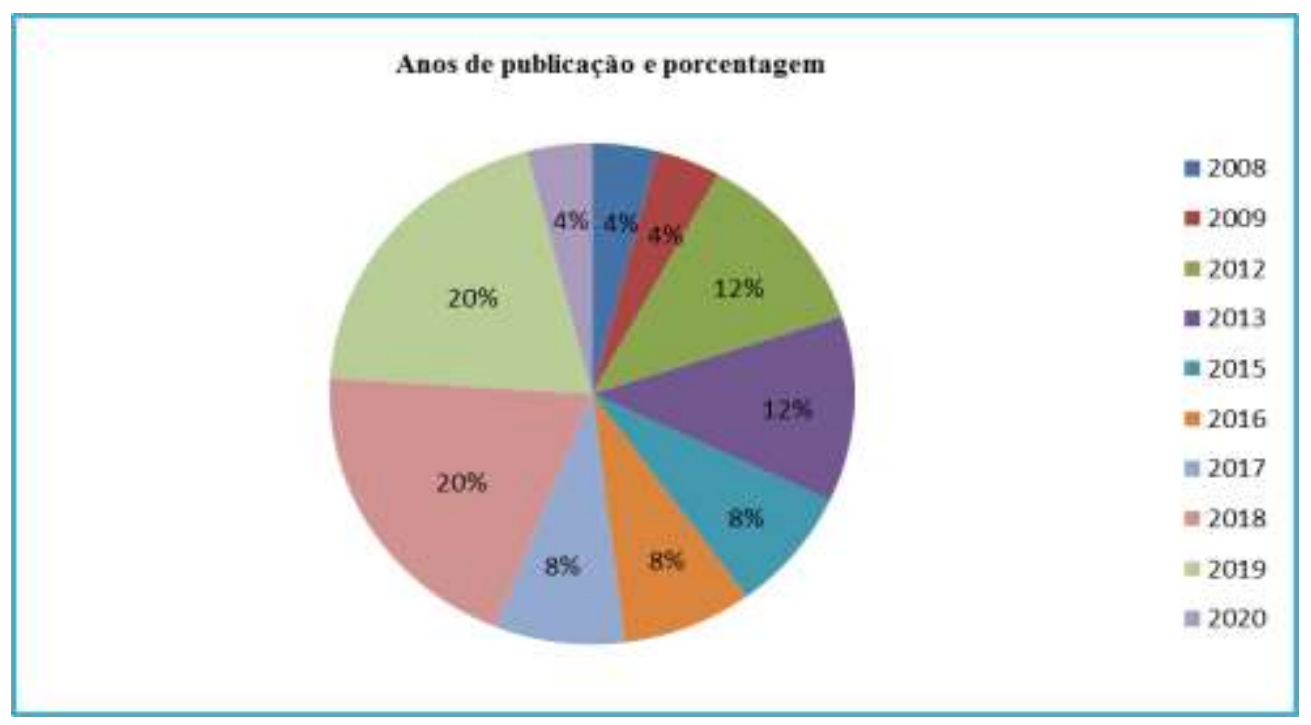

Fonte: Dados da pesquisa (2020).

Diante do gráfico ilustrado acima, constata-se que no ano de 2008 houve (4\%) das publicações, 2009 (4\%), 2012 (12\%), 2013 (12\%), 2015 (8\%), 2016 (8\%), 2017 (8\%), 2018 (20\%), 2019 (20\%), e 2020 (4\%), alcançando um total geral de 25 artigos $(100 \%)$, para serem trabalhados na elaboração do presente estudo.

O estresse é alvo de diversos estudos, evidenciado como exposições constantes a algumas condições físicas ou mentais estressoras que podem potencializar um conjunto de reações fisiológicas que alteram a homeostase e promovem impactos nocivos na saúde dos seres humanos. Tem-se o estresse ocupacional, como característica, o conjunto de fenômenos subjetivos vivenciados internamente e externamente, de modo individual e distinto frente aos estressores no ambiente laboral, sendo o efeito da influência mútua e excessiva do trabalho e dos recursos impostos, em longo prazo, capaz de resultar na 
alteração da psicofisiologia do trabalhador, propiciando o elevado índice de absenteísmo que onera o Estado, o trabalhador e o empregador (Moura et al., 2019).

Segundo Moura et al (2019), concentram-se, nas UTI's, profissionais especializados e recursos tecnológicos de ponta, para lidar com pacientes em situações graves. Dessa forma, apresentando o desgaste físico e mental, muitas vezes, silenciosamente, e o corpo reflete este desgaste com alguns sinais e sintomas despercebidos, na maioria das vezes, pelos profissionais.

As Unidades de Terapias Intensivas demonstram que os profissionais de enfermagem que atuam nesses ambientes enfrentam elevados níveis de estresse. Existe uma relação muito próxima entre a exposição diária a fatores estressores relacionados ao ambiente desgastante e cansativo e o estresse. No entanto, ressalta-se que, além dos fatores ambientais, estão também presentes os relacionados à gravidade do paciente, a rapidez na tomada de decisões, a assistência permanente e especializada, a alta complexidade tecnológica e rotinas exigentes (Zavalis et al., 2019).

Ao se considerar que os efeitos do estresse sob o indivíduo estão diretamente relacionados ao tempo de exposição e intensidade dos fatores estressores, verifica-se que a cronicidade do estado de estresse pode diminuir as funções cognitivas do indivíduo e, aliado a constantes eventos cotidianos, causam irritação, além de influenciar negativamente os processos assistenciais, a memória e a atenção. Os profissionais que desenvolvem suas atividades em UTI convivem diariamente com condições relacionadas ao processo de trabalho que podem apresentar-se como fatores estressores. Entende-se por fator estressor, o estímulo que inicia uma reação estressante, podendo trazer benefícios ou danos que causem emoções ao indivíduo (Zavalis et al., 2019).

O estresse tem sido definido como um conjunto de respostas do organismo a um evento ou situação que ultrapassa os recursos que o indivíduo possui no momento para enfrentar, englobando várias dimensões objetivas e subjetivas $\mathrm{O}$ estresse pode ser considerado um processo, ou seja, uma cadeia de eventos e acontecimentos e não uma reação única, sendo que a resposta fisiológica ao estresse é fundamental para lidar com as adversidades da vida, uma vez que mobiliza recursos para que o indivíduo se afaste do perigo iminente ou o enfrente, aumentando sua capacidade funcional. Quando o estresse é constante ou excessivo, torna-se prejudicial, podendo causar sensação de desgaste mental e físico, acompanhados por falhas intermitentes da memória, apatia, falta de atenção, baixa autoestima e desinteresse pelas coisas que até então davam prazer, comprometendo, assim, a qualidade de vida do indivíduo (Mello, Reis, \& Ramos, 2018).

Os profissionais de saúde, particularmente os que trabalham em Unidades de Terapia Intensiva (UTIs), estão em situação de vulnerabilidade para o desenvolvimento de quadros de estresse. Em uma UTI, a rotina de trabalho é marcada pela variabilidade, incerteza e risco, fatores que podem ser desencadeadores de estresse para muitos profissionais; além disso, o excesso de ruídos, o relacionamento com a equipe e a relação com os familiares e pacientes podem ser fontes adicionais de estresse nesse contexto (Mello, Reis, \& Ramos, 2018).

O estresse no ambiente de trabalho é um problema atual que apresenta riscos para a saúde mental. Segundo dados da Organização Mundial da Saúde, cerca de $90 \%$ da população mundial é afetada pelo estresse, tomando proporções de uma epidemia global. Nesse sentido, o estresse ocupacional na área da saúde está associado às situações específicas como problemas de relacionamento, ambiguidade e conflito de funções, dupla jornada de trabalho e casa, pressões exercidas pelos superiores de acordo com a percepção do indivíduo e alterações que sofre dentro do contexto de sua atividade. (Monte, Lima, Neves, Studart, \& Dantas, 2013).

A Unidade de Terapia Intensiva é percebida pela equipe que nela atua, assim como por pacientes e familiares, como um dos ambientes mais agressivos, tensos e traumatizantes do hospital. Dentre os fatores presentes no ambiente de terapia intensiva que geram estresse na equipe, encontram-se: pouco preparo para lidar com a constante presença de mortes, frequentes situações de emergência, falta de pessoal e material, ruído constante das aparelhagens, despreparo para lidar com as frequentes 
mudanças do arsenal tecnológico, sofrimento dos familiares, grau de responsabilidade em tomadas de decisão, conflito no relacionamento entre os profissionais, dentre outros (Monte, Lima, Neves, Studart, \& Dantas, 2013).

A Unidade de Terapia Intensiva é um setor de atendimento a pacientes críticos, assistidos ininterruptamente, no qual o profissional vivencia uma ansiedade diante das emergências da unidade, da morte do paciente, favorecendo o estresse. O enfermeiro assume uma postura de alerta constante devido às características próprias da rotina de serviço desse setor. As tentativas de melhoria do trabalho na Unidade de Terapia Intensiva são importantes, fatores como o aumento do número de funcionários, a estrutura física permitindo o acesso rápido aos materiais e equipamentos nos casos de emergência e por último, formas de amenizar o nível de barulho da unidade (Monte, Lima, Neves, Studart, \& Dantas, 2013).

O enfermeiro é um profissional com condições estressantes de trabalho e presta assistência em setores considerados desgastantes como a Unidade de Terapia Intensiva, tanto pela carga de trabalho como pela especificidade das tarefas. Existe a constante presença de óbitos, frequentes situações de emergência, controle de material utilizado e equipamentos, atender as necessidades dos familiares, realizar atividades com tempo mínimo disponível, falta de pessoal e material, ruído constante dos aparelhos, o sofrimento e angústia dos familiares. O profissional enfermeiro precisa conhecer e compreender as diversas situações que surgem diante de um internamento dentro da UTI, e não se deter somente à cura ou cuidados paliativos do paciente sem se dar conta que por trás daquela pessoa existem várias outras que estão envolvidas e sofrendo com a situação. Na Unidade de Terapia Intensiva, o enfermeiro deve ter condições mínimas de material e pessoal para se dedicar a prestar uma assistência efetiva e eficaz diante das intercorrências, que são muito comuns nesse setor (Monte, Lima, Neves, Studart, \& Dantas, 2013).

No que se refere ao profissional Enfermeiro, ressalta-se que este desempenha muitas atividades com alto grau de dificuldade e responsabilidade, as quais consistem em fatores psicossociais que condicionam a presença do estresse no trabalho que, quando associado ao ritmo acelerado, às jornadas excessivas e ao trabalho em turno podem resultar em estresse ocupacional. Desse modo, a atuação no ambiente hospitalar, em especial em Unidade de Terapia Intensiva (UTI), o trabalhador merece atenção especial porque, há maior quantidade de estressores do que em outras unidades de internação. A saber, a UTI é um ambiente fechado, com iluminação artificial, com rotinas aceleradas, em que são utilizados equipamentos sofisticados e barulhentos para o atendimento de pacientes/clientes em estado grave, cuja possibilidade de morte se faz presente em todo o momento. Em um ambiente assim, os enfermeiros podem não conseguir desenvolver estratégias de enfrentamento e adoecer em razão de seu labor, especialmente aqueles que atuam no período noturno, pelo fato de este tempo ser um estressor adicional (Versa et al., 2012).

Tem-se então que o estresse decorrente do trabalho noturno pode trazer prejuízos à qualidade de vida do trabalhador e para o seu desempenho profissional, resultando em redução na eficácia e na eficiência das atividades desempenhadas. Estudos sobre a influência do estresse na enfermagem atuante em UTI apontam que esse problema de saúde gera dificuldade de atenção e de concentração no profissional o que, sem dúvida compromete a qualidade do cuidado prestado (Versa et al., 2012).

Estresse é um problema atual, estudado por vários profissionais, pois apresenta risco para o equilíbrio normal do ser humano. Há cada vez mais uma preocupação com a saúde dos trabalhadores para que os danos sejam evitados e segundo a Organização Mundial de Saúde (OMS) há um favorecimento da saúde física e mental quando o trabalho se adapta às condições do trabalhador e quando os riscos para a sua saúde estão sobre controle (Guerrer, \& Bianchi, 2008).

A UTI é uma unidade onde se encontram internados pacientes que necessitam de cuidados diretos e intensivos, pois seu quadro de saúde pode facilmente evoluir para a morte; além disso, é considerado um setor fechado onde o entrosamento com outros setores é bastante diminuído. A assistência prestada à pacientes em UTI é bastante polêmica, se de um lado ela requer intervenções rápidas, de outro, não se tem dúvida de que são espaços naturalmente mobilizadores de emoções e sentimentos que frequentemente se expressam de forma muito intensa. Ser enfermeiro na UTI envolve a realização de um 
trabalho permeado por ambiguidades, aspectos gratificantes e limitantes que estão presentes no seu mundo e na vida (Guerrer, \& Bianchi, 2008).

No âmbito da saúde, os profissionais de enfermagem, estão frequentemente envolvidos nas relações humanas. Dada à complexidade do relacionamento interpessoal, intra-profissional e multiprofissional, somadas às exigências da profissão, estes profissionais podem adoecer devido à sua atividade de trabalho. Na Unidade de Terapia Intensiva, um serviço de alta complexidade, exige-se dos profissionais de enfermagem uma atuação constante e precisa. Uma vez que o profissional atua junto a pacientes graves, é necessário que os mesmos tenham conhecimentos técnico-científicos para lidar com as perdas. Dessa forma, alguns fatores do trabalho em enfermagem, em especial na UTI podem ser avaliados como excedentes aos recursos dos trabalhadores e leva-los ao estresse (Silva1 et al., 2016).

Alguns fatores que desencadeiam o estresse podem comprometer a qualidade de vida, podendo afetar um indivíduo como um todo, principalmente no seu desempenho profissional. Nesse sentido, a enfermagem incorpora alto nível de responsabilidade, na tentativa de ter o controle absoluto, sobre o trabalho que muitas vezes o levam a ter atitudes sobrehumanas. $\mathrm{O}$ trabalho nos dias atuais é um fator gerador de estresse. Contudo, se o profissional souber identificar quais são os fatores que o estresse pode causar, e de alguma forma, souber lidar com o que lhe incomoda pode melhorar sua qualidade de trabalho e de vida. Nesse contexto, a preocupação com o sofrimento, a dor e a morte vivenciada frequentemente, é entendido como uma avaliação que o indivíduo faz das situações aos quais é exposto como sendo mais ou menos desgastante, e a enfermagem é uma profissão que requer grande demanda de atenção, compaixão, responsabilidade. E o enfermeiro quando lida com essas situações pode se sentir, irritado, deprimido e desapontado, atrapalhando o desempenho profissional e aumentando a ansiedade (Campos, Oliveira, \& Nunes, 2017).

Além disso, o nível de ansiedade e tensão provocado, sobretudo, pela elevada responsabilidade que a enfermagem enfrenta em seu cotidiano profissional, ocorre devido às consequências desse processo tais como: ambiente extremamente seco, refrigerado, fechado, iluminação artificial, ruído interno contínuo e intermitente, inter-relacionamento constante entre as mesmas pessoas da equipe durante o turno, bem como, a exigência excessiva de segurança, respeito e responsabilidade para o paciente, garantindo a qualidade da assistência. Contudo, é um trabalho desgastante, que exige horários rígidos, extensa jornada de trabalho e muitas vezes, por ter pouco número de funcionários de acordo com os leitos, para dar uma qualidade de assistência, gera uma sobrecarga de trabalho. Portanto, vale à pena ressaltar que a UTI é um setor de uma unidade hospitalar onde se encontram pacientes com patologias graves e que necessitam de cuidados intensivos, o que exige da equipe de enfermagem muita atenção, a todo o momento (Campos, Oliveira, \& Nunes, 2017).

A Síndrome do estresse apresenta três fases: A primeira fase é a de alarme. Entendida como um comportamento de adaptação no qual o organismo tem uma reação de ataque ou de fuga ao estressor. Reconhece-se nos dois casos, um estado de reação saudável ao estresse, visto que possibilita o retorno à situação de equilíbrio posterior à experiência estressante. Caracterizada por alguns sintomas nessa fase, surgem às taquicardias, as tensões crônicas, a cefaleia, uma sensação de esgotamento, pressão no peito, as hipocloremias, as extremidades frias, dentre outros. A segunda fase é a de resistência, na qual há persistência da fase de alerta, onde ocorre uma revelação de sintomas da esfera psicossocial, como isolamento social, ansiedade e medo, oscilação do apetite, roer de unhas, impotência sexual, entre outros, Assim, o organismo altera seus parâmetros de normalidade e centraliza a reação interna em um determinado órgão-alvo, desencadeando a Síndrome de Adaptação Local (SAL). A terceira é a fase de exaustão, que pelo alto consumo de energia e pelo excesso de atividades, o organismo encontra-se fatigado. Então, ocorre a falência do órgão mobilizado na SAL, manifestando-se sob a forma de doenças orgânicas (Campos, Oliveira, \& Nunes, 2017).

Os principais sinais e sintomas físicos de um indivíduo com alto nível de estresse são: calor, suor, cefaleia, fadiga, insônia, tensão muscular, taquicardia, epigastralgia e colite. Já entre os sinais psíquicos, mentais e emocionais, encontram-se o 
déficit de concentração e memória, alteração do humor, ansiedade, medo, irritabilidade, depressão, preocupação, frustração, e impaciência, o que em níveis intensos de tensão pode levar ao envelhecimento precoce e ocasionar uma série de doenças como o enfarte, úlceras e psoríase, podendo levar até a morte. Para poder identificar uma pessoa com estresse, basta observar as mudanças de seu comportamento, como: alterações de humor, atitudes agressivas com a equipe ou até mesmo com o paciente, esgotamento físico e mental diante das situações do cotidiano, autocontrole afetado. Estas alterações acarretam pessoas mais vulneráveis em todo o ambiente de trabalho. O nível de estresse excessivo pode gerar sentimento de desamparo e angustia, prejudicando a concentração, afetando o desempenho e a capacidade de supervisão do enfermeiro (Campos, Oliveira, \& Nunes, 2017).

O estresse ocasiona distúrbios biopsicossociais, incluindo: aumento da frequência cardíaca e da pressão arterial, sudorese, dores na musculatura, ansiedade, fadiga, irritabilidade, insônia, distúrbios alimentares, diminuição da capacidade de concentração e outros efeitos deletérios sobre o indivíduo, que mediante a intensificação dos estímulos é responsável pela queda do rendimento geral e prejuízo de sua saúde. O estresse também configura um fator predisponente para alterações do sono, visto que o ciclo sono/vigília está ligado à atividade hipotalâmica, onde a liberação do cortisol atua na indução da vigília. O elevado nível de estresse ocupacional ou profissional exerce influência devastadora sobre a saúde do trabalhador e, consequentemente, ao sistema de saúde, incluindo a assistência a pacientes e familiares (Trettene, Ferreira, Mutro, Tabaquim, \& Razera, 2016).

Os profissionais intensivistas estão constantemente expostos aos fatores estressantes, e por isso requerem atenção e cuidados, pois a qualidade da assistência depende de toda a equipe. A vulnerabilidade de cada indivíduo contribui ainda mais para seu adoecimento, por isso suas experiências desenvolvem diferentes maneiras de enfrentamento para as situações de estresse, se adaptando ao ambiente. Assim há a necessidade de uma análise individual de cada situação, para que a pessoa reconheça os fatores estressores e tome medidas de enfrentamento para as condições estressantes vivenciadas (Oliveira, \& Gonçalves, 2019).

Diante do exposto, pode-se afirmar que a enfermagem está entre as profissões que podem ser consideradas estressantes por estar vinculada ao cuidado com pessoas que necessitam de assistência, mediante a uma situação de dor. A esse respeito à enfermagem, é considerada como estressante, por esta relacionada ao trabalho com pessoas doentes que requerem grande demanda de compaixão, sofrimento e simpatia. O enfermeiro, que vivencia esta situação em seu cotidiano, pode desenvolver irritabilidade, depressão, culpa e estes sentimentos são considerados estressores e podem influenciar negativamente no desenvolvimento profissional, o que poderá acarretar o aumento da ansiedade (Ribeiro et al., 2019).

Assim, os enfermeiros que atuam na UTI desempenham um papel fundamental na recuperação dos pacientes que necessitam de cuidados intensivos permanentes, por ter um quadro de saúde instável, pode agravar até a morte. Apesar de o enfermeiro estar envolvido na assistência de cuidados diretos ao paciente critico, em muitos momentos existe uma sobrecarga das atividades administrativas em relação às assistenciais, que estão ligadas de forma direta ao nível de habilidade e necessidade de respostas imediatas nos casos de emergências. Estas realidades vivenciadas pelos enfermeiros podem ocasionar o aumento da ansiedade, quando não obtido resultado satisfatório na realização das suas atribuições (Ribeiro et al., 2019).

Assim, entende-se que estudar a manifestação do estresse entre enfermeiros intensivistas permite compreender e elucidar alguns problemas, tais como a insatisfação profissional, a baixa produtividade no trabalho, o absenteísmo, os acidentes de trabalho e algumas doenças ocupacionais, além de permitir descobertas acerca de intervenções e busca de soluções (Ratochinski, Powlowytsch, Grzelczak, Souza, \& Mascarenhas, 2016). 


\section{Conclusão}

Evidenciou-se no estudo, que a UTI é percebida pela equipe de enfermagem, pelos pacientes e seus familiares, como um dos ambientes mais agressivos, tensos e traumatizantes do hospital. A Unidade de Terapia Intensiva é um ambiente intenso e requer do profissional que ali trabalha muita habilidade, agilidade e competência, além de constante atualização e disposição para atuar com humanização, na intenção de fazer um atendimento de qualidade. Faz-se necessária à criação e elaboração de medidas alternativas que minimizem a exposição ao estresse desse local, que favoreça a distração, a recreação como forma de alívio de tensões.

Dessa forma, é de fundamental importância à implantação de programas de intervenção psicológica, visando à promoção de estratégias de enfrentamento do estresse e com foco na saúde do trabalhador, pode auxiliar os enfermeiros a enfrentarem a vulnerabilidade ao estresse presente em ambientes de UTI, de forma geral. Tais intervenções permitem que os profissionais de enfermagem que estejam em situações de estresse ampliem sua capacidade de gerir demandas, enfrentar estressores e promover modificações em condições ambientais passíveis de alteração, tais como aquelas ligadas às relações interpessoais e gestão do trabalho.

Nesse contexto, o enfermeiro e a instituição hospitalar devem reconhecer os estressores que estão presentes no trabalho e procurar mecanismos e estratégias de enfrentamento individual e coletivo para diminuir a ocorrência de estresse profissional. Assim, o ambiente de trabalho favorável ao exercício dos profissionais de Enfermagem contribui para um maior nível de satisfação profissional e menor nível de estresse. Deste modo, é importante pensar na prática profissional de enfermagem que seja caracterizada por estrutura, processos e valores que instrumentalizem o profissional da Enfermagem durante a prestação dos cuidados, bem como apoiem no controle do ambiente em que este cuidado é prestado.

Portanto, o trabalho na UTI é complexo, e para que a assistência seja eficiente precisa-se de um gerenciamento eficaz. A fim de que o trabalho possa ser realizado com eficiência e qualidade, alguns recursos se tornam necessários: planta física adequada, recursos materiais e humanos, profissionais qualificados, dentre outros. Porém, inúmeros problemas são detectados pela falta desses recursos essenciais, pois geralmente não respondem com eficiência à necessidade real da assistência ao paciente ou a instituição não viabiliza os recursos necessários. Nesse cenário, cabe ao enfermeiro encontrar maneiras de driblar os problemas e tentar prestar a assistência da melhor forma possível. Torna-se importante a realização de estudos futuros com a finalidade de ampliar a produção científica a respeito dessa temática tão relevante, sendo de suma importância, no sentido de aprofundar discussões que possam contribuir para a promoção da saúde e na melhoria da qualidade de vida desses profissionais.

\section{Referências}

Abrantes, R. S., \& do Carmo, A. P. (2020). A Unidade de Terapia Intensiva um ambiente estressante para os profissionais de enfermagem. Acta de Estudos Interdisciplinares, 2(1).

Araujo Fernande, B. F. G., Felizardo, C. A., Vieira, C. A., Santana, M. C. M., Alves, P., \& dos Santos, N. A. R. (2019). Estresse ocupacional em enfermeiros atuantes na Unidade de Terapia Intensiva. REMAS-Revista Educação, Meio Ambiente e Saúde, 9(1), 17-30.

Botelho, L. L. R., de Almeida Cunha, C. C., \& Macedo, M. (2011). O método da revisão integrativa nos estudos organizacionais. Gestão e sociedade, 5(11), 121-136.

Cabral, J. V. B., Neves, S. C., \& Oliveira, F. H. P. C. (2016). Estresse dos profissionais de enfermagem em Unidade de Terapia Intensiva (UTI). Rev eletrônica "Diálogos Acadêmicos, 11(2), 33-42.

Campassi, V. S. (2018). O Estresse Ocupacional no Enfermeiro na Unidade de Terapia Intensiva. Revista Eletrônica eF@ tec, 8(1), 9-9.

Coronetti, A., Nascimento, E. R. P. D., Barra, D. C. C., \& Martins, J. D. J. (2006). O estresse da equipe de enfermagem na Unidade de Terapia Intensiva: o enfermeiro como mediador. Arquivos catarinenses de medicina, 35(4), 36-43.

Ercole, F. F., Melo, L. D., \& Alcoforado, C. L. G. C. (2014). Revisão integrativa versus revisão sistemática. Rev Min Enferm, 18(1), 9-12. 
Gouveia, M. T. D. O., Torres, C. R. D., Costa, R. D. S., \& Robazzi, M. L. D. C. C. (2015). Avaliação do estresse e sintomas apresentados pelos enfermeiros de Unidades de Terapia Intensiva pediátricas. Rev. enferm. UFPE on line, 360-367.

Guerrer, F. J. L., \& Bianchi, E. R. F. (2008). Caracterização do estresse nos enfermeiros de Unidades de Terapia Intensiva. Revista da Escola de Enfermagem da USP, 42(2), 355-362.

Inoue, K. C., Versa, G. L. G. D. S., Murassaki, A. C. Y., Melo, W. A. D., \& Matsuda, L. M. (2013). Estresse ocupacional em enfermeiros intensivistas que prestam cuidados diretos ao paciente crítico. Revista Brasileira de enfermagem, 66(5), 722-729.

Mello, R. D. C. C., Reis, L. B., \& Ramos, F. P. (2018). Estresse em profissionais de enfermagem: importância da variável clima organizacional. Gerais: Revista Interinstitucional de Psicologia, 11(2), 193-207.

Mendes, K. D. S., Silveira, R. C. D. C. P., \& Galvão, C. M. (2008). Revisão integrativa: método de pesquisa para a incorporação de evidências na saúde e na enfermagem. Texto \& contexto enfermagem, 17(4), 758-764.

Monte, P. F., Lima, F. E. T., Neves, F. M. D. O., Studart, R. M. B., \& Dantas, R. T. (2013). Estresse dos profissionais enfermeiros que atuam na Unidade de Terapia Intensiva. Acta Paulista de Enfermagem, 26(5), 421-427.

Monteiro, J. K., Oliveira, A. L. L. D., Ribeiro, C. S., Grisa, G. H., \& Agostini, N. D. (2013). Adoecimento psíquico de trabalhadores de Unidades de Terapia Intensiva. Psicologia: Ciência e Profissão, 33(2), 366-379.

Moura, R. D. S., Saraiva, F. J. C., Santos, R. M. D., Rocha, K. R. D. S. L., Barbosa, V. M. D. S., Calles, A. C. D. N., \& Brasil Junior, J. E. C. (2019). Níveis de estresse da enfermagem nas Unidades de Terapia Intensiva. Rev. enferm. UFPE on line, 569-577.

Pereira, A. S., Shitsuka, D. M., Parreira, F. J., \& Shitsuka, R. (2018). Metodologia da pesquisa científica.

Preto, V. A., \& Pedrão, L. J. (2009). O estresse entre enfermeiros que atuam em Unidade de Terapia Intensiva. Revista da Escola de Enfermagem da USP, 43(4), 841-848.

Ratochinski, C. M. W., Powlowytsch, P. W. D. M., Grzelczak, M. T., Souza, W. C. D., \& Mascarenhas, L. P. G. (2016). O estresse em profissionais de enfermagem. Revista Brasileira de Ciências da Saúde, 20(4), 341-346.

Ribeiro, W. A., Coutinho, V. V. A., de Morais, M. C., da Silva Souza, D. M., de Souza Couto, C., de Oliveira, L. S., \& Mendes, J. A. (2019). Evidências e repercussões do estresse vivenciado pelos enfermeiros da Unidade de Terapia Intensiva. Revista Pró-UniverSUS, 10(1), 81-85.

Rodrigues, T. D. F. (2012). Fatores estressores para a equipe de enfermagem da Unidade de Terapia Intensiva. Revista Mineira de Enfermagem, 16(3), 454462.

Silva, G. D. S. A. D., Silva, G. A. V. D., Silva, R. M. D., Andolhe, R., Padilha, K. G., \& Costa, A. L. S. (2018). Estresse e burnout em profissionais de enfermagem de Unidade de Terapia Intensiva e Semi-Intensiva. Revista de Divulgação Científica Sena Aires, 7(1), 5-11.

Silva, J. L. L. D., Soares, R. D. S., Costa, F. D. S., Ramos, D. D. S., Lima, F. B., \& Teixeira, L. R. (2015). Fatores psicossociais e prevalência da síndrome de burnout entre trabalhadores de enfermagem intensivistas. Revista Brasileira de Terapia Intensiva, 27(2), 125-133.

Soares, C. B., Hoga, L. A. K., Peduzzi, M., Sangaleti, C., Yonekura, T., \& Silva, D. R. A. D. (2014). Revisão integrativa: conceitos e métodos utilizados na enfermagem. Revista da Escola de Enfermagem da USP, 48(2), 335-345.

Sousa, L. M. M., Marques-Vieira, C. M. A., Severino, S. S. P., \& Antunes, A. V. (2017). A metodologia de revisão integrativa da literatura em enfermagem. No21 Série 2-Novembro 2017, 17.

Souza, M. T. D., Silva, M. D. D., \& Carvalho, R. D. (2010). Revisão integrativa: o que é e como fazer. Einstein, 8(1), $102-106$.

Souza, V. R., da Silva, J. L. L., Lopes, M. R., dos Santos, J. M., Silva, B. P., \& dos Santos, L. C. G. (2012). O estresse de enfermeiros atuantes no cuidado do adulto na Unidade de Terapia Intensiva. Revista de Pesquisa Cuidado é Fundamental Online, 4, 25-28.

Souza, V. S., da Silva, D. S., Lima, L. V., Teston, E. F., dos Santos Benedetti, G. M., Costa, M. A. R., \& Mendonça, R. R. (2018). Qualidade de vida dos profissionais de enfermagem atuantes em setores críticos. Revista cuidarte, 9(2), 2177-86.

Teixeira, L. B., Veloso, L. U. P., Ribeiro, Í. A. P., de Oliveira, T. N., \& Cortez, A. C. L. (2017). Estresse ocupacional na enfermagem atuante na Unidade de Terapia Intensiva. Investigación en Enfermería: Imagen y Desarrollo, 19(2), 195-211.

Trettene, A. D. S., Costa, R. B. D., Prado, P. C., Tabaquim, M. D. L. M., \& Razera, A. P. R. (2018). Estresse realidade vivenciada por enfermeiros atuantes em um Centro de Terapia Intensiva. Rev. enferm. UERJ, e17523-e17523.

Versa, G. L. G. D. S., Murassaki, A. C. Y., Inoue, K. C., Melo, W. A. D., Faller, J. W., \& Matsuda, L. M. (2012). Estresse ocupacional: avaliação de enfermeiros intensivistas que atuam no período noturno. Revista Gaúcha de Enfermagem, 33(2), 78-85.

Zavalis, A., Paula, V. G. D., Machado, D. A., Marta, C. B., Perez Junior, E. F., \& Santiago, L. C. (2019). O nível de estresse dos enfermeiros na Unidade de Terapia Intensiva. Rev. pesqui. cuid. fundam. (Online), 205-210. 